\title{
Improved estimation of ice and water contents in alpine permafrost through constrained petrophysical joint inversion: The Hoher Sonnblick case study
}

\author{
Matthias Steiner ${ }^{1}$, Florian M. Wagner ${ }^{2}$, Theresa Maierhofer ${ }^{1}, 3$, Wolfgang \\ Schöner ${ }^{4}$, and Adrián Flores Orozco ${ }^{1}$
}

Right Running Head: Constrained joint inversion of SRT \& ERT

\begin{abstract}
${ }^{1}$ TU Wien, Department of Geodesy and Geoinformation, Research Unit Geophysics, Vienna, Austria. E-mail: matthias.steiner@geo.tuwien.ac.at; theresa.maierhofer@geo.tuwien.ac.at; adrian.flores-orozco@geo.tuwien.ac.at

${ }^{2}$ RWTH Aachen University, Institute for Applied Geophysics and Geothermal Energy, Aachen, Germany. E-mail: florian.wagner@eonerc.rwth-aachen.de

3University of Fribourg, Department of Geosciences, Fribourg, Switzerland.

${ }^{4}$ University of Graz, Department of Geography and Regional Science, Graz, Austria. E-mail: wolfgang.schoener@uni-graz.at
\end{abstract}




\section{ABSTRACT}

Quantitative estimation of subsurface water and ice contents is critical for the understanding and modeling of permafrost evolution in alpine regions. Geophysical methods permit the assessment of subsurface conditions in a non-invasive and quasi-continuous manner, and in particular the combination of Seismic Refraction Tomography (SRT) and Electrical Resistivity Tomography (ERT) through a petrophysical model can quantitatively estimate ground water and ice contents. For the Hoher Sonnblick (3106 m.a.s.I., Austrian Alps), we investigate the improved estimation of water and ice contents based on SRT, ERT and Ground-Penetrating Radar (GPR) data collected in June and October 2019. We solve for water and ice contents following different approaches, namely (1) the independent inversion and subsequent transformation of the imaging results to the target parameters through a petrophysical model, and (2) the petrophysical joint inversion (PJI) of the data sets. Supported by a synthetic study, we demonstrate that the incorporation of structural and porosity constraints in the PJI allows for an improved quantitative characterization of subsurface conditions. For our measurements at Hoher Sonnblick, the constrained PJI resolves a shallow debris layer characterized by high air content 
and porosity, on top of a layer with lower porosity corresponding to fractured gneiss, and the bedrock layer with the lowest porosity. For both time steps we found high water contents at the lower end of the investigated area. Substantial variations in the subsurface ice content resolved between June and October 2019 indicate a correlation between the high water content and the melt water discharge within the debris layer. Our results demonstrate that the constrained PJI permits an improved characterization of subsurface hydrological parameters in alpine permafrost environments.

\section{INTRODUCTION}

Permafrost is an essential component of the alpine cryosphere (Gruber and Haeberli, 2009) and thus, of the hydrosphere; its areal extent even exceeds that of the glacier covered area in the Alps (Boeckli et al., 2012). Changes in alpine permafrost have been linked to relevant consequences such as stability problems for infrastructure (e.g., roads, buildings) or increased natural hazard risk (e.g., rock falls, Duvillard et al., 2015). alpine regions represent also an important catchment and storage area for groundwater (Schrott, 1998). As shown by a series of studies, 
climate change is particularly pronounced in mountainous regions such as the Alps

(e.g., Pepin et al., 2015) and, if compared to the global changes, climate sensitivity for temperature in the Greater alpine Region was about twice as large as at the global level in the past (Böhm et al., 2001) and is expected to be also larger in the future (Gobiet et al., 2014).

Permafrost degradation in the Alps is correlated to this rise in air temperature (e.g., Harris et al., 2003; Noetzli and Gruber, 2009), although it should be noted that the response of permafrost to climate change is much more complex than a simple temperature signal effect, i.e., generally a response to the energy balance between atmosphere and soil (Sokratov and Barry, 2002). Permafrost is a thermally defined phenomenon referring to subsurface areas characterized by temperatures below $0^{\circ} \mathrm{C}$ for at least two consecutive years (Harris et al., 1988). However, such definition neither refers to the ice and water content in the subsurface, nor to freezing and thawing processes. Moreover, as noted by Mollaret et al. (2019), in fine grained environments, high contents of unfrozen water can still be observed at negative temperatures. In this regard, there is a growing interest in the development of accurate techniques to quantify ice and water contents in alpine environments and 
their evolution accompanying the increase in temperatures (Rogger et al., 2017;

Beniston et al., 2018; Jones et al., 2019). Such investigations permit the assessment of variations in the ice-water interchange between the atmosphere and the cryosphere, and the associated seasonal and annual variations. Boreholes facilitate the in-situ measurement of parameters of interest, such as temperature (e.g., Global Terrestrial Network for Permafrost; Biskaborn et al., 2015), soil moisture (e.g., Pellet et al., 2016) and ice content (through borehole nuclear magnetic resonance logs, e.g., Parsekian et al., 2013; Kass et al., 2017). Due to the logistic challenges associated with the drilling of boreholes in alpine environments and related installation costs, the number and spatial distribution of boreholes is limited in the Alps. Moreover, investigations solely based on borehole data typically require interpolation, which might bias the spatial resolution of the results and their interpretation. Geophysical methods provide means for permafrost investigations with high spatial resolution in a non-invasive manner (see Hauck and Kneisel (2008) for an overview).

Based on the contrasting electrical properties of water and ice, and the linear correlation between electrical resistivity and temperature, Electrical Resistivity 
Tomography (ERT) is one of the most widely used geophysical methods to delineate frozen materials in the subsurface and to differentiate between unfrozen and frozen water content (e.g., Hauck and Vonder Muhll, 2003; Hilbich et al., 2008; Krautblatter et al., 2010; Kneisel et al., 2014; Dafflon et al., 2016; Emmert and Kneisel, 2017; Oldenborger and LeBlanc, 2018; Mollaret et al., 2019; Farzamian et al., 2020). However, the ERT measurements might be affected by poor signal-to-noise ratio $(\mathrm{S} / \mathrm{N})$ due to limited current densities injected in compacted frozen rocks and snow covered surfaces (e.g., Supper et al., 2014; Mollaret et al., 2019). As an alternative approach, Seismic Refraction Tomography (SRT) is a geophysical method based on the propagation of elastic waves and is used in permafrost research due to its sensitivity to changes in the mechanical properties in the subsurface due to freeze and thaw processes (Hilbich, 2010; Schöner et al., 2012b; Krautblatter and Draebing, 2014; Pogliotti et al., 2015; Draebing, 2016; Rogger et al., 2017). Yet, the SRT method cannot be easily automated for monitoring purposes. Moreover, SRT data might also be affected by low S/N for measurements collected in areas with difficult terrain (e.g., a debris covered slope) where the geophones are poorly coupled to the ground, and the hammer blows might result in seismic waves with low amplitudes. 
Contactless instruments have also been explored in permafrost studies, and among them, the Ground Penetrating Radar (GPR) method has become a well-established technique (Hinkel et al., 2001; Hauck and Kneisel, 2008; Hubbard et al., 2013; Rogger et al., 2017). The GPR method relies on the propagation of electromagnetic waves and is used in permafrost investigations to delineate lithological units and the contact to frozen materials in the subsurface based on their dielectrical properties (Hausmann et al., 2007; Schöner et al., 2012b; Monnier and Kinnard, 2013; Merz et al., 2016). Rough topography, however, might impair the quality of GPR data, for instance due to variable separation between the antenna and the surface. Moreover, during the melt season, an increase in the electrical conductivity causes a rapid attenuation of the electromagnetic waves and thus, a reduced depth of investigation (Annan, 2005).

Considering the challenging conditions in alpine permafrost investigations, the combination of different geophysical methods aims at reducing the limitations of single techniques, and thereby gaining a better site characterization. Moreover, this multi-method approach reduces the ambiguity in the interpretation of results obtained with a single geophysical method, and benefits from the partially complementary 
sensitivities of the different methods to the physical subsurface properties (e.g., ERT,

SRT and GPR). The processing of multi-method geophysical data sets can follow

different strategies, such as: (1) conventional inversion followed by joint

interpretation, (2) constrained inversion, and (3) joint inversion. Yet, the inversion of

geophysical data is an ill-posed problem (e.g., Zhdanov, 2002; Lesparre et al., 2017),

which means that it is affected by non-uniqueness and instability. Non-uniqueness

refers to the fact that the same data set can be sufficiently described by different

models, whereas instability refers to the fact that small changes in the data lead to large changes in the obtained inversion results.

In joint interpretation approaches, the different data sets are processed independently, i.e. generally by conventional inversion, and subsequently joined for a qualitative interpretation (e.g., Hausmann et al., 2007; Hubbard et al., 2013; Pogliotti et al., 2015; Rogger et al., 2017; Kunz and Kneisel, 2020). For permafrost investigations, Hauck et al. (2011) proposed the so-called four-phase model (4PM), where ERT and SRT results obtained through independent inversions are transformed to estimates of the subsurface water, ice and air contents (e.g., Schneider et al., 2013; Pellet et al., 2016; Hauck et al., 2017; Mewes et al., 2017). 
However, the quantitative interpretation based on the 4PM might result in the estimation of physically implausible parameters, i.e., negative values that cannot occur in nature (e.g., Hauck et al., 2011; Mewes et al., 2017; Wagner et al., 2019; Mollaret et al., 2020). Constrained inversion approaches enhance the consistency of results obtained through different geophysical methods by including complementary data, e.g., structural information, towards an improved estimation of physical parameters (Karaoulis et al., 2011; Doetsch et al., 2012; Robinson et al., 2013; Chou et al., 2016). The quantitative interpretation of the obtained results still requires the subsequent application of a petrophysical model such as the 4PM to retrieve parameters of interest such as the ice of water content. Joint inversion approaches simultaneously invert different geophysical data sets to improve the consistency in the resolved model(s). Structural joint inversion approaches exploit the common sensitivity of different geophysical methods for structural features (e.g., Haber and Oldenburg, 1997; Gallardo and Meju, 2003, 2004; Doetsch et al., 2010; Garofalo et al., 2015; Linde and Doetsch, 2016; Hellman et al., 2017; Ronczka et al., 2017), whereas petrophysical joint inversion (PJI) approaches rely on a model describing the relationship between different geophysical methods through one or more 
common petrophysical parameters (e.g., Gao et al., 2012; Zhang and Revil, 2015;

Sun and Li, 2016; Rücker et al., 2017; Wagner et al., 2019). With regard to

permafrost research, the PJI framework developed by Wagner et al. (2019) permits

the estimation of water, ice, air and rock contents using apparent electrical

resistivities and seismic traveltimes simultaneously, leveraging upon Archie's law and the time-averaging equation applied by the 4PM . Wagner et al. (2019) and Mollaret et al. (2020) demonstrate the benefits of the PJI, namely (1) the physical plausibility of the obtained results, i.e., no negative values in the fractional contents, (2) the possibility to incorporate non-geophysical measurements (e.g., temperature or soil moisture), and (3) the possibility to estimate a porosity model, due to the fact that the underlying petrophysical equations including are honored during the parameter estimation. Despite these advantages, both studies emphasize that the results obtained through the PJI still suffer from non-uniqueness, in particular with regard to the ice and rock contents as both components are characterized by relatively high acoustic velocities and act as electrical insulators (provided that surface conductivity is negligible, which might not be the case, e.g., Duvillard et al., 2018). This means that depending on the a priori input and inversion settings (e.g., lower and upper 
limits of a particular phase), the algorithm can produce a multitude of ice and rock matrix distributions, which equally well explain a single set of ERT and SRT data sets.

Our study intends to improve the characterization of the subsurface conditions at the summit of Hoher Sonnblick (Austria), at $3106 \mathrm{~m}$ above sea level (Schöner et al., 2012a). The study area is particularly relevant for several reasons, e.g., it hosts the Sonnblick Observatory, where climate change has been observed since 1886 and as permafrost degradation also affects the stability of the observatory buildings. However, only few studies have addressed the investigation of subsurface conditions, in particular the monitoring of permafrost degradation. So far, Schöner et al. (2012b) conduct the most detailed study at Hoher Sonnblick by combining geophysical and direct investigations, but only for a single time in 2012. In our study, we collected ERT and SRT data sets at two different times, which correspond approximately to the beginning and the end of the melt season. Moreover, GPR is used to obtain structural information in the near-surface and to support the interpretation of the seismic and electric inversion results. In particular, we extend the approach from Schöner et al. (2012b) by considering not only seismic but also 
electric data sets to estimate the water and ice content based on the 4PM. Taking into account the known limitation of this conventional approach, e.g., the physical implausibility of the resolved values, we aim to improve these estimates through the PJI of the seismic and electric data sets. Moreover, we explore the possibility to further improve the quantitative estimates for the water and ice contents by considering structural and porosity constraints in the PJI. In a first step, we investigate the incorporation of structural information derived through joint interpretation of SRT, ERT and GPR results, and complementary data. Such constraints aim at an improved delineation of lithological boundaries by combining the benefits of constrained and petrophysically coupled joint inversion. In a second step, we define a porosity distribution based on the analysis of time-lapse imaging results and use this information as a petrophysical constraint in the PJI. We hypothesize that porosity information from multiple time-steps is essential for improved estimates of ice and water contents. For an evaluation of our approach, we also present here a numerical study, which permits a quantitative comparison of the deviations from the real model in terms of the water, air, ice and rock content resolved by different inversion strategies. 


\section{MATERIALS AND METHODS}

\section{Petrophysical joint inversion solving for water, ice, air and rock content}

To image the changes in ice and water contents at Hoher Sonnblick, we use

the open-source PJI framework developed by Wagner et al. (2019), built on the

modeling and inversion functionality provided by pyGIMLi (Rücker et al., 2017).

Wagner et al. (2019) implement the underlying equations also used in the four-phase model (4PM) developed by Hauck et al. (2011) to describe the petrophysical relation between the electrical resistivity $(\rho)$ and the seismic velocity $(v$, commonly expressed by its reciprocal the seismic slowness $s$ ). According to Hauck et al. (2011),

permafrost systems are composed by the volumetric fractions of four phases, namely the solid rock matrix $f_{r}$, and water $f_{w}$, ice $f_{i}$, air $f_{a}$ filling the pore space, related by the volume conservation constraint

$f_{r}+f_{w}+f_{i}+f_{a}=1$

To describe the seismic slowness, the 4PM uses a modification of the Timur (1968) equation, a time-averaging equation summing up the individual seismic velocities of 
the four phases weighted by their corresponding volumetric fraction (Hauck et al.,

$S=\frac{1}{v}=\frac{f_{w}}{v_{w}}+\frac{f_{i}}{v_{i}}+\frac{f_{a}}{v_{a}}+\frac{f_{r}}{v_{r}}$

Assuming that electrolytic conduction dominates, the bulk electrical resistivity can be linked to the pore water content $\left(f_{w}\right)$ by Archie's second law (Archie, 1942)

$\rho=\rho_{w}\left(1-f_{r}\right)^{-m}\left(\frac{f_{w}}{1-f_{r}}\right)^{-n}$

where the Archie parameters $m$ and $n$ denote the cementation exponent and the saturation exponent, respectively, and $\rho_{w}$ corresponds to the pore water resistivity.

The volumetric fractions of the four phases for each model cell are elements of the parameter vector $\boldsymbol{p}=\left[\boldsymbol{f}_{\boldsymbol{w}}, \boldsymbol{f}_{\boldsymbol{i}}, \boldsymbol{f}_{\boldsymbol{a}}, \boldsymbol{f}_{\boldsymbol{r}}\right]^{T}$, which permits the estimation of physically plausible values, i.e., positive values, for each phase and enables the flexible incorporation of prior information. During parameter estimation, elements in the transformed model vector are computed as $m_{j}^{k}=\log \left(p_{j}^{k}\right)-\log \left(1-p_{j}^{k}\right)$, where the use of logarithmic barriers ensures that the petrophysical target parameters $\boldsymbol{p}$ vary between zero and one. The data vector $\boldsymbol{d}$ is composed of observed seismic 
traveltimes and logarithmic apparent resistivities, i.e.d $=\left[\boldsymbol{t}, \log \left(\boldsymbol{\rho}_{\boldsymbol{a}}\right)\right]^{T}$. The inversion scheme minimizes the objective function (following the notation in Zhdanov and Lin (2017)):

$$
\begin{aligned}
\phi(\boldsymbol{m})=\| \boldsymbol{W}_{d}\left(\boldsymbol{d}-F(\boldsymbol{m}) \|_{2}^{2}\right. & +\alpha^{2}\left\|\boldsymbol{W}_{m} \boldsymbol{m}\right\|_{2}^{2} \\
& +\beta^{2}\left\|\boldsymbol{W}_{p}^{\text {sum }} \boldsymbol{p}-\mathbf{1}\right\|_{2}^{2}+\gamma^{2}\left\|\boldsymbol{W}_{p}\left(\boldsymbol{p}-\boldsymbol{p}_{\mathbf{0}}\right)\right\|_{2}^{2} \rightarrow \min
\end{aligned}
$$

The first term of the objective function presented in equation 4 specifies the misfit between the observed data $\boldsymbol{d}$ and the model response $F(\boldsymbol{m})$ considering the reciprocals of the data errors on the diagonal of the data weighting matrix $\boldsymbol{W}_{d}$. The second term describes a smoothness regularization applied to the model vector $\boldsymbol{m}$, where $\alpha$ denotes the dimensionless smoothness regularization parameter chosen to fit the data within their respective error bounds. The spatial regularization matrix $\boldsymbol{W}_{m}$ controls the smoothness in the distribution of each component of the four-phase system. The third term is another regularization term required to ensure the adherence to the volume conservation constraint (equation 1), where $\beta$ denotes the corresponding dimensionless regularization parameter which, when chosen 
accordingly, restrains non-physical solutions. The matrix $\boldsymbol{W}_{p}^{\text {sum }}$ consists of four adjacent identity matrices and acts on the parameter vector $p$ to promote solutions for which the sum of the four volumetric fractions is close to unity. The fourth term in the objective function is optional and permits the incorporation of a priori knowledge regarding the petrophysical target parameters (Wagner et al., 2019). Prior information on one or more target parameters are concatenated in the reference and starting model vector $\boldsymbol{p}_{0}$. The square matrix $\boldsymbol{W}_{p}$ contains ones along its diagonal for target parameters to be kept close to the corresponding reference model and zeros otherwise. This term is scaled by using $\gamma=\beta$ to penalize solutions for which the resolved models deviate from the reference models or omitted by using $\gamma=0$ in case no prior information should be considered during the parameter estimation.

The incorporation of structural constraints in conventional inversion of geophysical data is a widely used practice to enhance contrasts in models resolved through conventional inversion (e.g., Günther et al., 2011; Doetsch et al., 2012; Bergmann et al., 2014; Wagner et al., 2015). Günther et al. (2011) implement structural constraints by adding structural information to the spatial regularization matrix used during the inversion. The spatial regularization matrix $\boldsymbol{W}_{m}$ in equation 4 is 
a block matrix and holds four first-order finite-difference roughness operators $(\boldsymbol{C})$ on

its diagonal to promote smoothness in each individual volumetric fraction:

$W_{m}=\left[\begin{array}{llll}C & \mathbf{0} & \mathbf{0} & \mathbf{0} \\ \mathbf{0} & \boldsymbol{C} & \mathbf{0} & \mathbf{0} \\ \mathbf{0} & \mathbf{0} & \boldsymbol{C} & \mathbf{0} \\ \mathbf{0} & \mathbf{0} & \mathbf{0} & \boldsymbol{C}\end{array}\right]$

The matrix $\boldsymbol{C}$ has as many rows as cell boundaries exist in the mesh (lines separating adjacent triangles in 2D and triangles/quadrangles separating tetrahedral/hexahedra when moving to 3D) and as many columns as model cells. Based on structural joint interpretation of complementary geophysical data, we set rows in $C$ corresponding to expected lithological discontinuities to zero. This effectively allows, but does not enforce, the inversion to develop sharp parameter contrasts, which would not be possible in conventional smoothness-constrained inversions.

An important data fit measure is the error-weighted chi-square fit $\chi^{2}=\frac{\phi_{d}}{N}$ where $\phi_{\boldsymbol{d}}$ is the first summand in equation 4 and $N$ is the number of measurements. A value of $\chi^{2}=1$ means that the data are described by the model within their respective error bounds (Günther et al., 2006; Günther and Rücker, 2019). All 
inversion results presented in this study have $\chi^{2}$ values close to one for synthetic

data and $0.8-1.2$ for field data.

\section{The study area at Hoher Sonnblick (Austria)}

The Hoher Sonnblick located at the border between the federal states of

Salzburg and Carinthia (Austria) is a mountain of the Goldberggruppe in the Austrian

Central Alps (Figure 1a). The Goldberggruppe is characterized by a north-west

striking gneiss zone ('Sonnblick-Gneisskern'; Exner, 1964) mainly consisting of granite gneiss with a predominant portion of potash feldspar (Exner, 1962). The summit of Hoher Sonnblick (Figure 1b) is formed by three steep rock walls facing towards East, North and North-East (indicated in Figure 1a). Our study area is located on the South-West facing slope (Figure 1c) covered by debris predominantly consisting of small to large blocks (Figure 1d). Subsurface conditions within the study area correspond to a three-layer case with the debris cover on top followed by a layer of fractured rocks and the bedrock (e.g., Schöner et al., 2012b). Direct information regarding the thickness of the fractured rock layer can be inferred from drill logs and the length of rock bolts; yet, such information is solely available for the rock walls 
(Figure 2a). In Figure 2b we present average air temperatures for Hoher Sonnblick indicating that the melt season approximately extends from May to October. Rock temperatures measured in boreholes provide information about the active layer thickness (ALT) as shown for borehole A in Figure 2c. Nonetheless, subsurface investigations within the study area are rare (e.g., Schöner et al., 2012b) and no permanent geophysical monitoring of permafrost is available.

\section{Acquisition and processing of geophysical data sets}

To assess changes in the subsurface properties associated to freezing and thawing processes, we collected geophysical data along a profile located on the South-West facing slope of the Hoher Sonnblick summit (indicated in Figure 1a). As illustrated by the thermal states in both the atmosphere (Figure $2 \mathrm{~b}$ ) and the subsurface (Figure 2c), the first data set was collected on 27 June 2019 approximately at the beginning of the melt season, whereas the second data set was acquired on 18 October 2019 at the end of the melt season. Measurements were conducted with 32 electrodes (ERT) and geophones (SRT), deployed with a separation of $2 \mathrm{~m}$ and hammer blows for the collection of the SRT data conducted at 
each geophone position. In June 2019 , the study area was covered by a snow layer

with a thickness ranging between approximately 0.5 and $2.0 \mathrm{~m}$; thus, to ensure galvanic contact between the ground and the electrodes and firm coupling between the ground and the geophones, we dug 32 holes in the snow cover to place both the geophones and the electrodes. We surveyed the positions of these holes with differential GNSS (dGNSS) to enable redeployment of the sensors at the same locations in October 2019.

SRT data collection and processing

For the seismic refraction surveys at Hoher Sonnblick, we used the DMT Summit acquisition system and vertical geophones with a corner frequency of $30 \mathrm{~Hz}$ deployed at the surface. To ensure a firm coupling between the geophones and the ground, we drilled holes in larger boulders of the debris cover to take up the spikes of the geophones. At the shot positions, we generated elastic waves with a $7.5 \mathrm{~kg}$ sledgehammer striking a $3 \mathrm{~cm}$ thick plastic plate and stacked four hammer blows to improve the S/N. Picking of first break traveltimes was done with a python script based on the ObsPy toolbox (Beyreuther et al., 2010) which provides the means for 
reading and processing of seismic waveform data. We applied a $120 \mathrm{~Hz}$ low-pass

filter on the seismic traces to attenuate signals associated to high frequency noise.

Yet, the S/N remained low - especially at larger offsets - requiring manual correction of automatically picked first onsets. Based on different gathers, i.e. common shot, receiver and offset, we managed to determine 992 and 991 traveltimes for the June and October data set, respectively.

\section{ERT data collection and processing}

ERT data were acquired using the eight-channel Multi-Phase Technologies

DAS-1 Electrical Impedance Tomography System. To facilitate sufficiently low contact resistances, we (1) coupled two stainless steel electrodes with a copper wire, (2) deployed such electrode couples in pre-drilled holes, (3) filled the remaining voids in the holes with quartz sand, and (4) saturated the sand with salt water. The method used by the DAS-1 to estimate contact resistances is limited to approximately $300 \mathrm{k} \Omega$, whereas readings above $200 \mathrm{k} \Omega$ are considered to be an open circuit. For both campaigns conducted at the Hoher Sonnblick, contact resistances were well below $100 \mathrm{k} \Omega$ for most electrodes. Similar values were reported by Mollaret et al. 
(2019) for different permafrost sites in the Swiss Alps. In October 2019, we observed values up to $140 \mathrm{k} \Omega$ for some electrodes and one electrode had to be excluded due to contact resistances of more than $200 \mathrm{k} \Omega$. For the data collection, we prepared a measurement protocol combining multiple gradient and dipole-dipole configurations, varying in the size of the voltage dipole in the range between 1.0 and 4.0 times the electrode spacing (i.e., skip 0 - 3 as for example described by Flores Orozco et al., 2018) leading to higher S/N than other configurations. Measurements were collected using a square wave form with a pulse length of $0.125 \mathrm{~s}$, and $50 \%$ duty cycle. We collected normal and reciprocal readings, where reciprocal refers to re-collecting data for each quadrupole with interchanged current and potential dipoles (Binley et al., 1995). After removing erroneous measurements related to negative apparent resistivity readings or zero current injection, followed by the removal of readings with poor reciprocity (e.g., Flores Orozco et al., 2012; Flores Orozco et al., 2018) out of 276 normal readings initially acquired 110 readings remained for both campaigns. 
For the conventional inversion $(\mathrm{Cl})$ of the observed traveltimes and collected apparent resistivity values for each individual time step, we used the corresponding modules of pyGIMLi (Rücker et al., 2017), whereas the PJI framework (Wagner et al., 2019) was used for the joint inversion of the data sets. We considered an estimated absolute SRT data errors of $2.5 \mathrm{~ms}$ and $2.0 \mathrm{~ms}$ for the inversion of the seismic data in June and October, respectively. Relative errors of $7.5 \%$ and $3.0 \%$ were used for the inversion of ERT measurements in June and October, respectively, corresponding to the standard deviation of the misfit between normal and reciprocal readings. All inversions, i.e. conventional and $\mathrm{PJI}$, were conducted a 4:1 preferential smoothing in the horizontal direction, i.e., a four times larger horizontal smoothing.

\section{GPR data collection and processing}

The GPR survey aimed at delimiting the thickness of the debris cover along the seismic and electric profile. Information about lithological contacts is needed in our study to structurally constrain the PJI under investigation. GPR measurements were conducted in June 2019, when conditions permitted to drag the antennas on the top of the snow for an improved data quality. We used a shielded antenna with a 
Geophysics

center frequency of $200 \mathrm{MHz}$ connected to a GSSI SIR-3000 system operated in time-based collection mode (120 scans per second). The SIR 3000 system was configured to apply 32 stacks for each trace to improve the $\mathrm{S} / \mathrm{N}$ and to store the raw radargram with 512 samples per trace with a time range of $250 \mathrm{~ns}$. With the commercial software ReflexW (Sandmeier, 2020), we processed the raw radargram by applying (1) a time zero correction, (2) a de-wow filter, (3) a $100-400 \mathrm{MHz}$ bandpass Butterworth filter, and (4) gain correction. We applied an elevation correction based on the dGNSS data measured along the profile. For the time-depth conversion, we considered a velocity of $0.13 \mathrm{~m} / \mathrm{ns}$ as obtained from the optimal stack power of observed diffraction hyperbolas.

The processed radargram showed a first strong reflection associated to the interface between snow and debris cover, high reflection amplitudes within the debris layer and lower amplitudes for the frozen bedrock. To verify such interpretation, we performed numerical modeling of electromagnetic wave propagation by means of the finite-difference scheme implemented in the ReflexW modeling module (Sandmeier, 2020) following an approach similar to Hausmann et al. (2007). To validate our interpretation, we computed synthetic radargrams with varying values of the 
dielectrical permittivity $(\varepsilon)$ and electrical conductivity $(\sigma)$ and considering different geometries of the subsurface interfaces. Moreover, we included near-surface heterogeneities, i.e., water and air-filled voids, to model the internal structure of the debris. Assessing the agreement between synthetic and measured radargrams enabled refinement of the parameters in the numerical model and thus, to validate the interpretation of the signatures observed in the GPR data.

\section{RESULTS}

\section{Assessing the reconstruction capabilities of different inversion approaches}

In a first step, we conduct a synthetic study to quantify deviations in the water, air, ice and rock contents resolved through different inversion approaches, taking into account that it is practically impossible to obtain continuous spatial information about the true physical and thermal properties of the subsurface at real field conditions. For our numerical investigations we build a model in 2D without topography consisting of three horizontal layers and parameterize the layers according to values expected for Hoher Sonnblick. Based on this model, we compute synthetic seismic and electric data sets considering geophones, shots and electrodes to be collocated at 32 
stations with a separation of $2 \mathrm{~m}$. The computed traveltimes are subjected to additive Gaussian white noise (AGWN) with a standard deviation of $0.5 \mathrm{~ms}$. For the simulation of apparent resistivity measurements we use the same configuration as in the field and apply a normally distributed relative error of $5 \%$. From these synthetic data sets we estimate water, air, ice and rock contents through (1) the independent inversion of data sets and subsequent application of the 4PM, (2) the PJI (as applied by Wagner et al. (2019) and Mollaret et al. (2020)), (3) the structurally constrained PJI, and (4) the PJI with structural and porosity constraints. The parameterization of the petrophysical model used in the conventional and the PJI approaches is based on the values summarized in Table 1.

The synthetic study permits the evaluation of how inaccurate prior information used as constraints in the PJI affect the resolved water, air, ice and rock contents. Hence, we defined five different scenarios (summarized in Table 2) referring to correct and erroneous prior information regarding the depth of the interface between the top and intermediate layer (shallow interface), the depth of the interface between the intermediate and bottom layer (deep interface), and the porosity model. To facilitate a clear comparison of the true model with the models resolved through the 
different inversion approaches, in Figure 3 we present the results of our synthetic study in form of 1D curves extracted in the center of the inverted models. The values of the true model for each component are indicated in Figure 3 for a direct evaluation of the results. Assuming a homogeneous porosity of $30 \%$, the independent inversion of the data sets and subsequent application of the 4PM resolves the main structural characteristics, i.e. the layering, of the true model and the estimated values approximate the true water and air content. Yet in terms of the ice content, the results obtained through this conventional approach suffer from negative values in the nearsurface. Moreover, the ice content in the intermediate layer is underestimated, whereas at depth the resolved values are too high. The unconstrained PJI yields similar results for the water and air content as the conventional approach, provides an estimate of the true rock content and solves for a non-negative ice content. Although the ice content resolved within the top layer is a good estimate for the true values, at larger depths the estimated ice content fails to resemble the true model. To overcome such limitations, we include prior knowledge in the PJI to reduce the degrees of freedom and, thus, provide improved estimates for the different fractional values. In Scenario 1 we incorporate the true interface depths as structural 
constraints in the PJI and invert the synthetic data sets based on a homogeneous

porosity distribution. The results presented in Figure 3a illustrate that for the water content and to a lesser extent for the air content the structural characteristics of the true model are accurately resolved and also the obtained values are a good approximation of the true values. With regard to the ice and rock content, the incorporation of structural information does not yield the true values. As illustrated in Figure $3 b$, prescribing the true porosity distribution ensures that the values of the true models are accurately resolved. Results obtained through the structurally constrained PJI based on (partially) erroneous prior knowledge, defined by Scenarios 2 to 5 (Figure 3a), illustrate that the estimated water and air contents do not significantly deviate from the true values. However, the resolved ice and rock content models do not reflect the true structures and values. For the PJI with porosity constraints, we approximate the true porosity distribution by k-nearest neighbor smoothing of the true values (where $\mathrm{k}=100$ model cells) and subsequent adding of normally distributed noise. In Scenarios 4 and 5 we additionally distort the approximated porosity distribution by $\pm 15 \%$ to simulate gross errors in the a priori porosity information. As illustrated in Figure 3b, the estimates for the water and air content still solve for the 
true values. In case of the ice and rock content we observe large variations in the

resolved values dependent of the prescribed porosity model. Still, the estimates clearly resemble the general characteristics of the true model and approximate the true fractional values. Hence, our synthetic study demonstrates that the results obtained through the PJI are significantly improved by incorporating a petrophysical constraint that at least roughly resembles the true subsurface porosity distribution. We also note here that this sensitivity of the 4PM, underlying the PJI framework, was already described by Hauck et al. (2011).

\section{Subsurface structures resolved at Hoher Sonnblick through joint interpretation}

Figure 4 presents the processed radargram and the imaging results obtained through independent inversion of the seismic and electrical data sets collected at different acquisition times in June and October 2019. The SRT solves for similar structures for June (Figure 4a) and October 2019 (Figure 4b). Nonetheless, we observed substantial variations in the resolved seismic velocities in the near surface, while seismic velocities are consistently resolved with values higher than $4000 \mathrm{~m} / \mathrm{s}$ for June and October 2019 at depths above approximately 8 m. Likewise, we 
delineate similar structures in the ERT imaging results for both June (Figure 4c) and

October 2019 (Figure 4d). Yet, the resolved resistivity values show a general decrease of approximately $60 \%$ from June to October 2019 , which can be explained by the inverse correlation between resistivity and temperature (e.g., Krautblatter et al., 2010; Zisser et al., 2010; Bairlein et al., 2016). Still, the structural consistency of the ERT results for both times clearly indicates that the electrical images are related to lithological contacts, whereas the amplitude of the values is controlled by variations in the water content (Mollaret et al., 2019).

The interpretation of the independently processed and inverted data sets (i.e., joint interpretation) enables derivation of a subsurface model that delineates the principal lithological units at the summit of Hoher Sonnblick. We consider the chaotic relationship between the reflections observed in the shallow areas of the radargram presented in Figure $4 \mathrm{e}$ to be associated to the debris cover. Based on this interpretation, the geometry of the debris layer can be delineated in the first half of the profile. Although not easily observable from the radargram, SRT and ERT consistently resolve an increase in the thickness of the debris layer in the lower part of the profile. Similar to Schöner et al. (2012b), we identify the possible interface 
between fractured and consolidated rocks at the contact to acoustic velocities higher than $4000 \mathrm{~m} / \mathrm{s}$. To approximate the geometry of the bedrock interface along the geophysical section, we fitted a cubic spline to the $4000 \mathrm{~m} / \mathrm{s}$ isolines computed from SRT results obtained for both times (see Figure $4 a$ and $4 b$ ). The agreement in the geometry of the seismic interface obtained from the two SRT data sets supports our interpretation that such an interface corresponds to the contact between fractured and consolidated rocks, which is likely not affected by seasonal variations. Combining the different structural information yields the lithological model presented in Figure 4f. The interpretation of SRT and GPR data previously collected at Hoher Sonnblick (Schöner et al., 2012b) supports the proposed lithological model. Moreover, the consistency in the main features observed across GPR, SRT and ERT in the near surface might demonstrate that these are controlled by the contact between the debris and the weathered gneiss. The increased thickness of the debris layer inferred from SRT and ERT images corresponds with weak reflections in the radargram suggesting the deposition of saturated fine-grained debris below the blocky material. However, the contact between the weathered gneiss and the bedrock is solely resolved from the SRT imaging results obtained through 
smoothness-constraint inversions. Hence, this interface requires further verification to be considered as a legible source for structural constraints.

In absence of direct information regarding the depth to the layer of consolidated rocks, we need to refer to the results of previous studies providing the corresponding information. Schöner et al. (2012b) infer the contact between fractured and compacted rocks through modeling of the thermal diffusivity based on rock temperatures observed in borehole $\mathrm{B}$. Their model indicated a distinctive change in the thermal diffusivity from $2.3 \times 10^{-6}$ to $0.5 \times 10^{-6} \mathrm{~m}^{2} / \mathrm{s}$ in a depth of approximately $8.8 \mathrm{~m}$. They attributed to the strong heat transfer from the surface down to a depth of $8.8 \mathrm{~m}$ to fractured rocks and interpreted the decreased heat transfer at larger depths to be associated to the compacted bedrock. Comparing the bedrock depth inferred from the thermal diffusivity model with a 1D representation of the resolved seismic velocities allowed for a verification of the SRT imaging results (Schöner et al., 2012b). This approach is not directly applicable for our study as our SRT profile does not cover the location of borehole B (cf. Figure 1a). Hence, in Figure 5 we provide a comparison of rock temperatures observed in borehole $A$ and seismic velocities in the vicinity of borehole $A( \pm 2 \mathrm{~m})$ with the bedrock depth reported by Schöner et al. 
(2012b). Note that the modeled bedrock depth needs to be corrected for the larger

debris cover thickness observed at borehole A, for instance in the GPR results presented in Figure 4e. Figure 5 illustrates that the reported bedrock depth coincides well with a distinct decrease in the variability of the rock temperatures, which we attribute to the reduced heat transfer in the bedrock. From the 1D seismic velocity curve we can infer a velocity of approximately $4000 \mathrm{~m} / \mathrm{s}$ for the compacted rocks at depth. In this regard, we consider our SRT imaging results to be verified by an approach based on direct borehole information and thus, consider the geometry of the $4000 \mathrm{~m} / \mathrm{s}$ isoline to be representative for the contact between fractured and consolidated rocks along the entire geophysical profile.

\section{Quantifying subsurface ice-water contents at Hoher Sonnblick}

Although the joint interpretation approach is commonly applied in multi-method investigations, the obtained results remain qualitative since they do not provide estimates of relevant parameters such as porosity, ice and water content. Nonetheless, SRT and ERT images can be transformed to quantitative results through a petrophysical model such as the 4PM. For the parameters of the 4PM, i.e., 
the variables in equations 2 and 3 , we use the values summarized in Table 1, which are common in permafrost literature (e.g., Hauck and Kneisel, 2008). We note here that literature values might represent a good approximation to highly heterogeneous materials such as debris and weathered rock. Considering the imaging results presented in Figure 4 and results from previous investigations (Schöner et al., $2012 b)$, we prescribe a porosity model characterized by a gradual decrease in the porosity with depth, where high values in the near-surface correspond to the debris layer and a low porosity at depth refers to the less weathered gneiss and bedrock. Based on the 4PM, the independent SRT and ERT imaging results can be transformed to water, air and ice contents. The fractional values obtained for the data sets collected in June and October 2019 are presented in Figure 6a. Blanked regions illustrate that this approach yields non-physical values, i.e., negative values, in the estimated ice and air contents. Based on the same petrophysical parameters and governing equations, the PJI framework solves for physically plausible values for each phase, i.e., water, ice, air and rock content for data collected in June and October 2019 (Figure 6b). Furthermore, in Figure 6c we present images resolved 
through structurally constrained PJI, which incorporates structural information from the lithological model obtained through joint interpretation.

Results illustrated in Figure 6 reveal consistent water contents resolved through different inversion approaches. The highest water content (approximately $20 \%$ ) is resolved in the near-surface within the debris cover, and within a deepseated anomaly located at the lower end of the profile; whereas a lower water content $(<10 \%)$ is found below the debris cover. Large variations can be observed in the estimated ice content following the different inversion approaches. Particularly, the ice contents estimated based on structural constraints show substantially lower values (< 10\% in June 2019 and $<5 \%$ in October 2019) than those obtained through the conventional approach and the unconstrained PJI (> 10\% for June 2019 and up to $20 \%$ for October 2019 ). In case of the air content, similar values are resolved through the conventional approach and the PJI. A high air content is resolved for the debris layer, with values up to $10 \%$ in June and $30 \%$ for measurements collected in October 2019. For June 2019 the structurally constrained PJI solves for higher air content values within the debris layer than the other approaches (approximately $10 \%$ points higher). As expected, both PJI approaches solved for the lowest rock contents 
(approximately $50 \%$ to $60 \%$ ) in the near-surface corresponding to the debris cover; whereas the rock content increases with depth and reaches maximum values in the bottom layer (up to $90 \%$ ); yet, the range of values differ significantly.

To investigate the consistency in the results obtained through different inversion approaches, we present in Figure 7 the computed time-lapse differences in the inverted parameters $\left(\Delta f_{x}=f_{x(o c t)}-f_{x(J u n)}\right.$ with $x=w, a, i, r$ for the water, air, ice, and rock content, respectively). The temporal changes in the water content are comparable for all three approaches showing similar patterns and a consistent range of values. In case of ice and rock content, the resolved temporal changes differ significantly for the different inversion approaches. The conventional inversion and subsequent application of the 4PM results in non-physical values for the ice content close to the near-surface; yet, a general decrease in the ice content is observed from June to October, as expected due to the higher temperatures in summer (Figure 2b). The unconstrained PJI yields an increase in the ice content in the upper part of the profile during the melt season, which is physically implausible, especially when compared with the increase in the ALT (c.f., Figure 2c). For the air content, the conventional approach and the unconstrained PJI resolve similar temporal changes; 
yet, in the conventional results the coverage at depth is limited due to non-physical

values. The temporal changes resolved through the structurally constrained PJI yield plausible values in the entire imaging plane, with an overall decrease in the ice content, which is in agreement with the expected increase in the subsurface temperatures during the melt season. Moreover, the structurally constrained PJI solves for a more detailed image of spatial variations in the air content within the debris cover than resolved through the other approaches. However, both PJI approaches resolve for temporal changes in the rock content implicating alterations in the rock-air matrix over the course of four months.

\section{DISCUSSION}

\section{Benefits and limitations of different PJI approaches}

The results of our synthetic study (c.f., Figure 3) illustrate that the PJI

framework provides the means to overcome the estimation of non-physical values as obtained through the conventional approach, which becomes evident in case of the near-surface ice content. Comparing the resolved values with the values of the true model demonstrates that the PJI also provides an improved estimation of the true ice 
and rock contents by allowing variations in the porosity during parameter estimation and honoring the volume conservation constraint (equation 1). Yet, the estimates for the ice and rock content provide only a rough approximation of the true model. As demonstrated by synthetic Scenario 1 (c.f., in Figure 3), the incorporation of prior knowledge, i.e., interface depths and porosity distribution, through the constrained PJI permits to accurately solve for the characteristics of the true model. The assumption of extensive and accurate existing information may be challenging for field investigations, where information might be scarce (for instance, at Hoher Sonnblick), or complementary data might be affected by uncertainties. Results obtained for Scenarios 2 to 5 illustrate that the true water and air content can still be quantitatively estimated in case of inaccurate prior information and thus demonstrate that the constrained PJI significantly improves the stability of the inversion. Considering that the estimates for the ice and rock content show a substantial sensitivity to changes in both the structural and porosity constraints, the constraints need to be carefully defined. Still, the models obtained through the constrained PJI approaches provide a sufficiently accurate approximation of the true model. The comparison with results obtained through the conventional approach and the PJI 
demonstrate that even inaccurate prior knowledge can improve the estimates for the

ice and rock content. In this regard, we consider the constrained PJI approaches to yield improved estimates compared to other inversion approaches.

\section{Improving the estimates for ice and water content at Hoher Sonnblick}

Similar to our synthetic study, the unconstrained PJI prevents the estimation of negative values in the ice content also for the field data collected at Hoher Sonnblick. However, considering other permafrost studies (e.g., Hauck, 2002; Hilbich et al., 2008) the resolved increase in the ice content during the summer months is physically implausible (Figure 7b). Aiming at an improved estimation for the fractional contents of each phase, we incorporate structural constraints in the PJI to enhance the consistency in the results obtained for both times (see Figure 6c). The corresponding temporal changes presented in Figure 7c illustrate that the structurally constrained PJI resolves a decrease in the ice content within the debris cover along the entire profile, as expected due to the higher air temperatures in summer (June to October; see Figure 2b and 2c) compared to the winter months. However, Figure $7 b$ and $7 c$ still report substantial changes in the rock content, which we consider 
physically implausible as the rock matrix should remain constant over the course of our investigation (approximately four months). Although the PJI framework demonstrably provides better estimates for the fractional contents in the different phases, Figure 7 demonstrates that this approach can still be limited due to the inherently similar physical properties of rock and ice, i.e., both materials are characterized by a high seismic velocity and a high electrical resistivity. In particular, porosity estimates will be largely biased since the 4PM underlying the PJI requires sufficiently high contrasts in the seismic velocities of rock and ice to distinguish between these two solid phases, a problem already highlighted by Hauck et al. (2011). Accordingly, temporal variations in the seismic velocities might result in implausible estimations of the ice and rock content, as observed in Figure $7 \mathrm{~b}$ and $7 \mathrm{c}$. Prescribing the a priori information regarding the porosity distribution would be a step towards the estimation of physically plausible values (e.g., Hauck et al., 2011), which refers to the incorporation of a petrophysical constraint in the PJI. Laboratory estimations of porosity values in rock samples, however, might be not representative for the bulk porosity of the different subsurface layers, i.e., the debris cover or the weathered gneiss observed at Hoher Sonnblick (see c.f., Figure 1). Borehole 
information are not available at the site, which is not equipped for subsurface investigations on the same level as other study areas (Mollaret et al., 2019).

Moreover, such information might be valid only at the borehole position, thus, limiting its application in an imaging framework. To overcome the lack of ground truth, we propose to use the porosity distribution resolved through $\mathrm{PJI}$ for one time step as a petrophysical constraint in the PJI of data collected at another time step to solve for improved estimates of the ice and water content. We consider this approach to be more concise and easier to apply at different sites than the approach used in, e.g., the study by Pellet et al. (2016), where the authors estimated the porosity distribution based on a modified petrophysical model, which was solely applicable in an unfrozen part of the study area. Assuming a minimum subsurface ice content at the end of the melt season, we suggest that the October 2019 rock content distribution resolved through the unconstrained PJI as the best possible estimation of the subsurface porosity distribution $\left(\Phi_{(O c t)}=1-f_{r(O c t)}\right)$ at Hoher Sonnblick.

Following the argumentation from Hauck et al. (2011), we prescribe the porosity model $\Phi_{(O c t)}$ as fixed in the PJI, i.e., we implement it a as a petrophysical constraint. Moreover, by prescribing $\Phi_{(O c t)}$ for June and October 2019, we couple the 
PJI of data sets collected at different times by means of a common parameter, which is kept constant in the inversion of two different time-lapses. In this regard, the proposed incorporation of the porosity distribution in the PJI can be seen as a timelapse constraint. Prescribing a fixed porosity decreases the degree of freedom in the PJI by penalizing variations in the rock content during the inversion. Following such an approach, we are able to increase the physical consistency between time steps, as required to solve for reliable changes in the parameters at different times, and improve the quantification of ice and water dynamics.

Figure $8 \mathrm{a}$ and $8 \mathrm{~b}$ present the results resolved through the structurally and time-lapse constrained PJI for June and October 2019, respectively. To assess seasonal variations in the different phases we compute absolute differences $\Delta f_{x}=$ $f_{x(o c t)}-f_{x(\text { Jun })}$ illustrated in Figure 8c. For the water content, variations are largely confined to the debris layer showing lateral variations along the profile. The highest increase in the water content (approximately $10 \%$ points) is resolved at the lower end of the profile, likely associated to melt water discharge, which can be observed in summer within this area of the Hoher Sonnblick summit. The temporal changes in the ice content indicate the largest ice loss ( -15\% points) within the debris layer in the 
upper part of the profile, i.e., close to the observatory building. Moreover, the area around the depression in the debris layer in the lower half of the profile (i.e., between $50 \mathrm{~m}$ and $70 \mathrm{~m}$ along profile direction) is characterized by a considerable decrease in the ice content $(\sim-10 \%$ points), potentially related to the infiltration and of warm melt water and rainwater. The air content mainly varies within the debris layer, when melting ice is replaced by air (approximately $20 \%$ points) indicated by the corresponding changes in these fractional contents. Reduced near-surface air contents can be related to an increase in the water content. We interpret the resolved variations in the different phases as a result of the increased available atmospheric energy input during the melt season, which results in melt water infiltration within the debris layer caused by the melting snow (e.g., in June) and near-surface ice.

\section{Outlook}

Further developments with regard to the PJI could address the incorporation of additional geophysical methods and monitoring data, both of which could potentially be added to the PJI framework in the form of a time-lapse joint inversion. Additionally, it might be worth to explore the possibility to impose time-lapse petrophysical 
constraints on selected phases, e.g., temperature dependent constraints on the ice content whereas the other phases remain unconstrained. Considering the expected system dynamics the use of individual spatial and temporal regularization strategies for the different phases should be investigated. Such an approach would allow the PJI, e.g., to solve for large contrasts in one parameter and use a smoothness constraint for another one, and thus, might permit to enhance the estimates for the constituents of the four phase system in both space and time.

With regard to the long-term permafrost monitoring at Hoher Sonnblick, we propose to establish a geophysical monitoring collecting seismic and electric data on an annual basis. This would allow to assess variations in the water and ice content, which in turn might help to get a better understanding of the groundwater system in the summit area. To obtain information regarding the water, air, ice and rock content for the entire summit area, we suggest to conduct SRT, ERT and GPR investigations along multiple profiles. Depending on the SRT measurement scheme such data set would permit a quasi-3D or even a real 3D PJI of ERT and SRT data in an alpine permafrost site. 


\section{CONCLUSION}

In our study, we presented the application of a petrophysical joint inversion

(PJI) scheme to solve for variations in subsurface water and ice contents and investigated the possibility to improve the quantitative reconstruction capabilities based on the incorporation of prior knowledge in the form of both structural and porosity constraints.

The results of the synthetic study highlighted that the PJI might not solve for the true rock and ice content due to the similar physical properties of rock and ice. Instead, the stability of the PJI can be improved by incorporating structural or petrophysical constraints, or a combination of both. Despite the substantial sensitivity of the estimates for the ice and rock content to inaccurate constraints, the values resolved through the constrained PJI still sufficiently approximate the true values and might even provide improved estimates compared to the independent inversion and the unconstrained PJI.

For our study at the summit of Hoher Sonnblick, we demonstrated that the collection of time-lapse data sets allows for the evaluation and improvement of the 
consistency in the water, air, ice and rock content models resolved through the PJI.

In agreement with our numerical study, the prescription of a common porosity model in the PJI for the different time steps permitted to overcome the estimation of implausible ice and rock contents in case of a weak contrast in the physical properties of these two phases. Based on our results, we conclude that the joint inversion of collocated seismic and electrical data sets permitted to extend our understanding about the subsurface conditions at the summit of Hoher Sonnblick and the accompanying seasonal changes.

\section{ACKNOWLEDGMENTS}

This research has been supported by the Swiss National Science Foundation (SNFS) (grant no. 200021L_178823) and received funds of the Austrian Academy of Sciences (ÖAW) granted through the project ATMOperm (Atmosphere-permafrost relationship in the Austrian Alps). Florian Wagner gratefully acknowledges funding received by the Dr. Erich Ritter foundation in cooperation with the Water Science Alliance. We thank Elke Ludewig and Claudia Riedl for granting us access to air and subsurface temperature data and drill logs from the Sonnblick Observatory. We also 
thank associated editor James Irving and three anonymous reviewers for their

suggestions and corrections that substantially improved the quality of the manuscript.

\section{REFERENCES}

Annan, A., 2005, Ground-penetrating radar, Near-surface geophysics: Society of Exploration Geophysicists, 357-438.

Archie, G. E., 1942, The electrical resistivity log as an aid in determining some reservoir characteristics: Transactions of the AIME, 146, no. 01, 54-62.

http://dx.doi.org/10.2118/942054-G.

Bairlein, K., M. Bücker, A. Hördt, and B. Hinze, 2016, Temperature dependence of spectral induced polarization data: experimental results and membrane polarization theory: Geophysical Journal International, 205, no. 1, 440453. http://dx.doi.org/10.1093/gji/ggw027.

Beniston, M., D. Farinotti, M. Stoffel, L. M. Andreassen, E. Coppola, N. Eckert, A. Fantini, F. Giacona, C. Hauck, M. Huss, H. Huwald, M. Lehning, J. I. LopezMoreno, J. Magnusson, C. Marty, E. Moran-Tejeda, S. Morin, M. Naaim, A. 
Provenzale, A. Rabatel, D. Six, J. Stotter, U. Strasser, S. Terzago, and C. Vincent, 2018, The European mountain cryosphere: a review of its current state, trends, and future challenges: Cryosphere, 12, no. 2, 759-794. http://dx.doi.org/10.5194/tc-12759-2018.

Bergmann, P., M. Ivandic, B. Norden, C. Rücker, D. Kiessling, S. Lüth, C. Schmidt-Hattenberger, and C. Juhlin, 2014, Combination of seismic reflection and constrained resistivity inversion with an application to 4D imaging of the CO 2 storage site, Ketzin, Germany: Geophysics, 79, no. 2, B37-B50. http://dx.doi.org/10.1190/GEO2013-0131.1.

Beyreuther, M., R. Barsch, L. Krischer, T. Megies, Y. Behr, and J. Wassermann, 2010, ObsPy: A Python Toolbox for Seismology: Seismological Research Letters, 81, no. 3, 530-533. http://dx.doi.org/10.1785/gssrl.81.3.530.

Binley, A., A. Ramirez, and W. Daily, 1995, Regularised image reconstruction of noisy electrical resistance tomography data: Proceedings of the 4th Workshop of the European Concerted Action on Process Tomography, Bergen, Norway, 401-410. 
Biskaborn, B. K., J. P. Lanckman, H. Lantuit, K. Elger, D. A. Streletskiy, W. L.

Cable, and V. E. Romanovsky, 2015, The new database of the Global Terrestrial Network for Permafrost (GTN-P): Earth System Science Data, 7, no. 2, 245-259. http://dx.doi.org/10.5194/essd-7-245-2015.

Boeckli, L., A. Brenning, S. Gruber, and J. Noetzli, 2012, Permafrost distribution in the European Alps: calculation and evaluation of an index map and summary statistics: Cryosphere, 6, no. 4, 807-820. http://dx.doi.org/10.5194/tc-6-8072012.

Böhm, R., I. Auer, M. Brunetti, M. Maugeri, T. Nanni, and W. Schöner, 2001, Regional temperature variability in the European Alps: 1760-1998 from homogenized instrumental time series: International Journal of Climatology: A Journal of the Royal Meteorological Society, 21, no. 14, 1779-1801. http://dx.doi.org/10.1002/joc.689.

Chou, T. K., M. Chouteau, and J. S. Dube, 2016, Intelligent meshing technique for 2D resistivity inverse problems: Geophysics, 81, no. 4, IM45-IM56.

http://dx.doi.org/10.1190/Geo2015-0177.1. 
Dafflon, B., S. Hubbard, C. Ulrich, J. Peterson, Y. X. Wu, H. Wainwright, and

T. J. Kneafsey, 2016, Geophysical estimation of shallow permafrost distribution and properties in an ice-wedge polygon-dominated Arctic tundra region: Geophysics, 81, no. 1, WA247-WA263. http://dx.doi.org/10.1190/Geo2015-0175.1.

Doetsch, J., N. Linde, I. Coscia, S. A. Greenhalgh, and A. G. Green, 2010, Zonation for 3D aquifer characterization based on joint inversions of multimethod crosshole geophysical data: Geophysics, 75, no. 6, G53-G64. http://dx.doi.org/10.1190/1.3496476.

Doetsch, J., N. Linde, M. Pessognelli, A. G. Green, and T. Gunther, 2012, Constraining 3-D electrical resistance tomography with GPR reflection data for improved aquifer characterization: Journal of Applied Geophysics, 78, 68-76. http://dx.doi.org/10.1016/j.jappgeo.2011.04.008.

Draebing, D., 2016, Application of refraction seismics in alpine permafrost studies: A review: Earth-science reviews, 155, 136-152.

http://dx.doi.org/10.1016/j.earscirev.2016.02.006. 
Duvillard, P.-A., L. Ravanel, and P. Deline, 2015, Risk assessment of infrastructure destabilisation due to global warming in the high French Alps: Journal of Alpine Research, no. 103-2. http://dx.doi.org/10.4000/rga.2896.

Duvillard, P. A., A. Revil, Y. Qi, A. S. Ahmed, A. Coperey, and L. Ravanel, 2018, Three-Dimensional Electrical Conductivity and Induced Polarization Tomography of a Rock Glacier: Journal of Geophysical Research-Solid Earth, 123, no. 11, 9528-9554. http://dx.doi.org/10.1029/2018jb015965.

Emmert, A., and C. Kneisel, 2017, Internal structure of two alpine rock glaciers investigated by quasi-3-D electrical resistivity imaging: Cryosphere, 11, no. 2, 841855. http://dx.doi.org/10.5194/tc-11-841-2017.

Exner, C. 1962, Geologische Karte der Sonnblickgruppe 1:50.000. In Geologische Karte der Republik Österreich 1:50.000: Geological Survey of Austria.

Exner, C. 1964, Erläuterungen zur geologischen Karte der Sonnblickgruppe 1: 50.000. Geological Survey of Austria. 
Farzamian, M., G. Vieira, F. A. M. Santos, B. Y. Tabar, C. Hauck, M. C. Paz, I.

Bernando, M. Ramos, and M. A. de Pablo, 2020, Detailed detection of active layer freeze-thaw dynamics using quasi-continuous electrical resistivity tomography (Deception Island, Antarctica): Cryosphere, 14, no. 3, 1105-1120.

http://dx.doi.org/10.5194/tc-14-1105-2020.

Flores Orozco, A., A. Kemna, and E. Zimmermann, 2012, Data error

quantification in spectral induced polarization imaging: Geophysics, 77, no. 3, E227-

E237. http://dx.doi.org/10.1190/GEO2010-0194.1.

Flores Orozco, A., M. Bücker, M. Steiner, and J.-P. Malet, 2018, Complexconductivity imaging for the understanding of landslide architecture: Engineering geology, 243, 241-252. http://dx.doi.org/10.1016/j.enggeo.2018.07.009.

Gallardo, L. A., and M. A. Meju, 2003, Characterization of heterogeneous near-surface materials by joint $2 \mathrm{D}$ inversion of dc resistivity and seismic data:

Geophysical Research Letters, 30, no. 13, 1658-1661.

http://dx.doi.org/10.1029/2003gl017370. 
Gallardo, L. A., and M. A. Meju, 2004, Joint two-dimensional DC resistivity and seismic travel time inversion with cross-gradients constraints: Journal of Geophysical Research-Solid Earth, 109, no. B3, B03311. http://dx.doi.org/10.1029/2003jb002716.

Gao, G. Z., A. Abubakar, and T. M. Habashy, 2012, Joint petrophysical inversion of electromagnetic and full-waveform seismic data: Geophysics, 77, no. 3, WA3-WA18. http://dx.doi.org/10.1190/Geo2011-0157.1.

Garofalo, F., G. Sauvin, L. V. Socco, and I. Lecomte, 2015, Joint inversion of seismic and electric data applied to 2D mediaSeismic and electric data joint inversion: Geophysics, 80, no. 4, EN93-EN104. http://dx.doi.org/10.1190/GEO20140313.1.

Gobiet, A., S. Kotlarski, M. Beniston, G. Heinrich, J. Rajczak, and M. Stoffel, 2014, 21st century climate change in the European Alps--a review: Sci Total Environ, 493, 1138-1151. http://dx.doi.org/10.1016/j.scitotenv.2013.07.050.

Gruber, S., and W. Haeberli, 2009, Mountain permafrost, Permafrost soils: 
Günther, T., and C. Rücker. 2019, Boundless Electrical Resistivity

Tomography BERT 2 - the user tutorial. https://gitlab.com/resistivity-net/bert.

Günther, T., C. Rücker, and K. Spitzer, 2006, Three-dimensional modelling and inversion of DC resistivity data incorporating topography-II. Inversion:

Geophysical Journal International, 166, no. 2, 506-517.

http://dx.doi.org/10.1111/j.1365-246X.2006.03011.x.

Günther, T., G. Schaumann, P. Musmann, and M. Grinat, 2011, Imaging of a fault zone by a large-scale dc resistivity experiment and seismic structural information: Near Surface 2011-17th EAGE European Meeting of Environmental and Engineering Geophysics.

Haber, E., and D. Oldenburg, 1997, Joint inversion: A structural approach: Inverse problems, 13, no. 1, 63-77. http://dx.doi.org/10.1088/0266-5611/13/1/006.

Harris, C., D. Vonder Muhll, K. Isaksen, W. Haeberli, J. L. Sollid, L. King, P. Holmlund, F. Dramis, M. Guglielmin, and D. Palacios, 2003, Warming permafrost in European mountains: Global and Planetary Change, 39, no. 3-4, 215-225. http://dx.doi.org/10.1016/j.gloplacha.2003.04.001. 
Geophysics

Harris, S. A., H. M. French, J. A. Heginbottom, G. H. Johnston, B. Ladanyi, D.

C. Sego, and R. O. van Everdingen, 1988, Glossary of permafrost and related

ground-ice terms, 142.

https://globalcryospherewatch.org/reference/glossary_docs/permafrost_and_ground_t

erms_canada.pdf.

Hauck, C., 2002, Frozen ground monitoring using DC resistivity tomography:

Geophysical Research Letters, 29, no. 21, 2016-2019.

http://dx.doi.org/10.1029/2002gl014995.

Hauck, C., and D. Vonder Muhll, 2003, Inversion and interpretation of two-

dimensional geoelectrical measurements for detecting permafrost in mountainous

regions: Permafrost and periglacial processes, 14 , no. 4, 305-318.

http://dx.doi.org/10.1002/ppp.462.

Hauck, C., and C. Kneisel, 2008, Applied geophysics in periglacial

environments: Cambridge University Press. 
Hauck, C., M. Bottcher, and H. Maurer, 2011, A new model for estimating

subsurface ice content based on combined electrical and seismic data sets:

Cryosphere, 5, no. 2, 453-468. http://dx.doi.org/10.5194/tc-5-453-2011.

Hauck, C., C. Hilbich, and C. Mollaret, 2017, A time-lapse geophysical model for detecting changes in ground ice content based on electrical and seismic mixing rules: 23rd European Meeting of Environmental and Engineering Geophysics, 2017, no. $1,1-5$.

Hausmann, H., K. Krainer, E. Brückl, and W. Mostler, 2007, Internal structure and ice content of reichenkar rock glacier (Stubai alps, Austria) assessed by geophysical investigations: Permafrost and periglacial processes, 18, no. 4, 351-367. http://dx.doi.org/10.1002/ppp.601.

Hellman, K., M. Ronczka, T. Gunther, M. Wennermark, C. Rucker, and T. Dahlin, 2017, Structurally coupled inversion of ERT and refraction seismic data combined with cluster-based model integration: Journal of Applied Geophysics, 143, 169-181. http://dx.doi.org/10.1016/j.jappgeo.2017.06.008. 
Hilbich, C., 2010, Time-lapse refraction seismic tomography for the detection

of ground ice degradation: Cryosphere, 4, no. 3, 243-259.

http://dx.doi.org/10.5194/tc-4-243-2010.

Hilbich, C., C. Hauck, M. Hoelzle, M. Scherler, L. Schudel, I. Voelksch, D. V.

Muehll, and R. Maeusbacher, 2008, Monitoring mountain permafrost evolution using electrical resistivity tomography: A 7-year study of seasonal, annual, and long-term variations at Schilthorn, Swiss Alps: Journal of Geophysical Research-Earth Surface, 113, no. F1. http://dx.doi.org/10.1029/2007jf000799.

Hinkel, K., J. Doolittle, J. Bockheim, F. Nelson, R. Paetzold, J. Kimble, and R. Travis, 2001, Detection of Subsurface Permafrost Features with GPR, Barrow, Alaska, USA, Permafrost and Periglac: Process. http://dx.doi.org/10.1002/ppp.369.

Hubbard, S. S., C. Gangodagamage, B. Dafflon, H. Wainwright, J. Peterson, A. Gusmeroli, C. Ulrich, Y. Wu, C. Wilson, J. Rowland, C. Tweedie, and S. D. Wullschleger, 2013, Quantifying and relating land-surface and subsurface variability in permafrost environments using LiDAR and surface geophysical datasets: 
Hydrogeology Journal, 21, no. 1, 149-169. http://dx.doi.org/10.1007/s10040-012-

0939-y.

Jones, D. B., S. Harrison, K. Anderson, and W. B. Whalley, 2019, Rock

glaciers and mountain hydrology: A review: Earth-science reviews, 193, 66-90.

http://dx.doi.org/10.1016/j.earscirev.2019.04.001.

Karaoulis, M. C., J. H. Kim, and P. I. Tsourlos, 2011, 4D active time

constrained resistivity inversion: Journal of Applied Geophysics, 73, no. 1, 25-34.

http://dx.doi.org/10.1016/j.jappgeo.2010.11.002.

Kass, M. A., T. P. Irons, B. J. Minsley, N. J. Pastick, D. R. N. Brown, and B. K. Wylie, 2017, In situ nuclear magnetic resonance response of permafrost and active layer soil in boreal and tundra ecosystems: Cryosphere, 11, no. 6, 2943-2955. http://dx.doi.org/10.5194/tc-11-2943-2017.

Kneisel, C., A. Emmert, and J. Kastl, 2014, Application of 3D electrical resistivity imaging for mapping frozen ground conditions exemplified by three case studies: Geomorphology, 210, 71-82.

http://dx.doi.org/10.1016/j.geomorph.2013.12.022. 
Krautblatter, M., and D. Draebing, 2014, Pseudo 3-DP wave refraction seismic monitoring of permafrost in steep unstable bedrock: Journal of Geophysical Research: Earth Surface, 119, no. 2, 287-299.

http://dx.doi.org/10.1002/2012JF002638.

Krautblatter, M., S. Verleysdonk, A. Flores Orozco, and A. Kemna, 2010, Temperature-calibrated imaging of seasonal changes in permafrost rock walls by quantitative electrical resistivity tomography (Zugspitze, German/Austrian Alps): Journal of Geophysical Research-Earth Surface, 115, no. F2. http://dx.doi.org/10.1029/2008jf001209.

Kunz, J., and C. Kneisel, 2020, Glacier-Permafrost Interaction at a Thrust Moraine Complex in the Glacier Forefield Muragl, Swiss Alps: Geosciences, 10, no. 6, 205. http://dx.doi.org/10.3390/geosciences10060205.

Lesparre, N., F. Nguyen, A. Kemna, T. Robert, T. Hermans, M. Daoudi, and A. Flores Orozco, 2017, A new approach for time-lapse data weighting in electrical resistivity tomography: Geophysics, 82 , no. 6 , E325-E333. 
Linde, N., and J. Doetsch, 2016, Joint Inversion in Hydrogeophysics and Near-

Surface Geophysics: Integrated imaging of the Earth: Theory and applications, 218,

119-135. http://dx.doi.org/10.1002/9781118929063.

Merz, K., H. Maurer, L. Rabenstein, T. Buchli, S. M. Springman, and M.

Zweifel, 2016, Multidisciplinary geophysical investigations over an alpine rock glacier:

Geophysics, 81, no. 1, WA1-WA11. http://dx.doi.org/10.1190/GEO2015-0157.1.

Mewes, B., C. Hilbich, R. Delaloye, and C. Hauck, 2017, Resolution capacity of geophysical monitoring regarding permafrost degradation induced by hydrological processes: Cryosphere, 11, no. 6, 2957-2974. http://dx.doi.org/10.5194/tc-11-29572017.

Mollaret, C., F. M. Wagner, C. Hilbich, C. Scapozza, and C. Hauck, 2020, Petrophysical Joint Inversion Applied to Alpine Permafrost Field Sites to Image Subsurface Ice, Water, Air, and Rock Contents: Frontiers in Earth Science, 8, -. http://dx.doi.org/10.3389/feart.2020.00085.

Mollaret, C., C. Hilbich, C. Pellet, A. Flores Orozco, R. Delaloye, and C. Hauck, 2019, Mountain permafrost degradation documented through a network of 
permanent electrical resistivity tomography sites: Cryosphere, 13, no. 10, 2557-2578. http://dx.doi.org/10.5194/tc-13-2557-2019.

Monnier, S., and C. Kinnard, 2013, Internal structure and composition of a rock glacier in the Andes (upper Choapa valley, Chile) using borehole information and ground-penetrating radar: Annals of Glaciology, 54, no. 64, 61-72. http://dx.doi.org/10.3189/2013AoG64A107.

Noetzli, J., and S. Gruber, 2009, Transient thermal effects in Alpine permafrost: Cryosphere, 3, no. 1, 85-99. http://dx.doi.org/10.5194/tc-3-85-2009.

Oldenborger, G. A., and A. M. LeBlanc, 2018, Monitoring changes in unfrozen water content with electrical resistivity surveys in cold continuous permafrost: Geophysical Journal International, 215, no. 2, 965-977. http://dx.doi.org/10.1093/gji/ggy321.

Parsekian, A. D., G. Grosse, J. O. Walbrecker, M. Muller-Petke, K. Keating, L. Liu, B. M. Jones, and R. Knight, 2013, Detecting unfrozen sediments below thermokarst lakes with surface nuclear magnetic resonance: Geophysical Research Letters, 40, no. 3, 535-540. http://dx.doi.org/10.1002/grl.50137. 
Pellet, C., C. Hilbich, A. Marmy, and C. Hauck, 2016, Soil Moisture Data for the Validation of Permafrost Models Using Direct and Indirect Measurement Approaches at Three Alpine Sites: Frontiers in Earth Science, 3.

http://dx.doi.org/10.3389/feart.2015.00091.

Pepin, N., R. S. Bradley, H. F. Diaz, M. Baraer, E. B. Caceres, N. Forsythe, H. Fowler, G. Greenwood, M. Z. Hashmi, X. D. Liu, J. R. Miller, L. Ning, A. Ohmura, E. Palazzi, I. Rangwala, W. Schoner, I. Severskiy, M. Shahgedanova, M. B. Wang, S. N. Williamson, D. Q. Yang, and M. R. I. E. W. Grp, 2015, Elevation-dependent warming in mountain regions of the world: Nature climate change, 5, no. 5, 424-430. http://dx.doi.org/10.1038/Nclimate2563.

Pogliotti, P., M. Guglielmin, E. Cremonese, U. M. di Cella, G. Filippa, C. Pellet, and C. Hauck, 2015, Warming permafrost and active layer variability at Cime Bianche, Western European Alps: Cryosphere, 9, no. 2, 647-661. http://dx.doi.org/10.5194/tc-9-647-2015.

Robinson, J., T. Johnson, and L. Slater, 2013, Evaluation of known-boundary and resistivity constraints for improving cross-borehole DC electrical resistivity 
imaging of discrete fractures: Geophysics, 78, no. 3, D115-D127.

http://dx.doi.org/10.1190/Geo2012-0333.1.

Rogger, M., G. B. Chirico, H. Hausmann, K. Krainer, E. Bruckl, P. Stadler, and G. Bloschl, 2017, Impact of mountain permafrost on flow path and runoff response in a high alpine catchment: Water Resources Research, 53, no. 2, 1288-1308. http://dx.doi.org/10.1002/2016wr019341.

Ronczka, M., K. Hellman, T. Gunther, R. Wisen, and T. Dahlin, 2017, Electric resistivity and seismic refraction tomography: a challenging joint underwater survey at Aspo Hard Rock Laboratory: Solid Earth, 8, no. 3, 671-682.

http://dx.doi.org/10.5194/se-8-671-2017.

Rücker, C., T. Günther, and F. M. Wagner, 2017, pyGIMLi: An open-source library for modelling and inversion in geophysics: Computers \& Geosciences, 109, 106-123. http://dx.doi.org/10.1016/j.cageo.2017.07.011.

Sandmeier, K. 2020, REFLEXW: Program for the Processing of Seismic, Acoustic or Electromagnetic Reflection. https://www.sandmeiergeo.de/download.html. 
Schneider, S., S. Daengeli, C. Hauck, and M. Hoelzle, 2013, A spatial and temporal analysis of different periglacial materials by using geoelectrical, seismic and borehole temperature data at Murtèl-Corvatsch, Upper Engadin, Swiss Alps:

Geographica Helvetica, 68, no. 4, 265-280. http://dx.doi.org/10.5194/gh-68-2652013.

Schöner, W., R. Böhm, and I. Auer, 2012a, 125 years of high-mountain research at Sonnblick Observatory (Austrian Alps)_from "the house above the clouds" to a unique research platform: Theoretical and Applied Climatology, 110, no. 4, 491-498. http://dx.doi.org/10.1007/s00704-012-0689-8.

Schöner, W., L. Boeckli, H. Hausmann, J.-C. Otto, S. Reisenhofer, C. Riedl, and S. Seren, 2012b, Spatial patterns of permafrost at Hoher Sonnblick (Austrian Alps)-extensive field-measurements and modelling approaches.

Schrott, L., 1998, The hydrological significance of high mountain permafrost and its relation to solar radiation. A case study in the high Andes of San Juan, Argentina: Bamberger Geographische Schriften, 15, 71-84. 
Sokratov, S. A., and R. G. Barry, 2002, Intraseasonal variation in the thermoinsulation effect of snow cover on soil temperatures and energy balance:

Journal of Geophysical Research: Atmospheres, 107, no. D10.

http://dx.doi.org/10.1029/2001JD000489.

Sun, J. J., and Y. G. Li, 2016, Joint inversion of multiple geophysical data using guided fuzzy c-means clustering: Geophysics, 81, no. 3, ID37-ID57. http://dx.doi.org/10.1190/Geo2015-0457.1.

Supper, R., D. Ottowitz, B. Jochum, A. Romer, S. Pfeiler, S. Kauer, M. Keuschnig, and A. Ita, 2014, Geoelectrical monitoring of frozen ground and permafrost in alpine areas: field studies and considerations towards an improved measuring technology: Near Surface Geophysics, 12, no. 1, 93-115. http://dx.doi.org/10.3997/1873-0604.2013057.

Timur, A., 1968, Velocity of Compressional Waves in Porous Media at Permafrost Temperatures: Geophysics, 33, no. 4, 584-595. http://dx.doi.org/10.1190/1.1439954. 
Geophysics

Wagner, F. M., C. Mollaret, T. Gunther, A. Kemna, and C. Hauck, 2019,

Quantitative imaging of water, ice and air in permafrost systems through

petrophysical joint inversion of seismic refraction and electrical resistivity data:

Geophysical Journal International, 219, no. 3, 1866-1875.

http://dx.doi.org/10.1093/gji/ggz402.

Wagner, F. M., P. Bergmann, C. Rucker, B. Wiese, T. Labitzke, C. Schmidt-

Hattenberger, and $\mathrm{H}$. Maurer, 2015, Impact and mitigation of borehole related effects

in permanent crosshole resistivity imaging: An example from the Ketzin $\mathrm{CO} 2$ storage

site: Journal of Applied Geophysics, 123, 102-111.

http://dx.doi.org/10.1016/j.jappgeo.2015.10.005.

Zhang, J., and A. Revil, 2015, 2D joint inversion of geophysical data using

petrophysical clustering and facies deformation: Geophysics, 80, no. 5, M69-M88.

http://dx.doi.org/10.1190/Geo2015-0147.1.

Zhdanov, M. S., 2002, Geophysical inverse theory and regularization

problems. Vol. 36: Elsevier. 
Geophysics

Zhdanov, M. S., and W. Lin, 2017, Adaptive multinary inversion of gravity and gravity gradiometry dataAdaptive multinary inversion of gravity data: Geophysics, 82, no. 6, G101-G114.

Zisser, N., A. Kemna, and G. Nover, 2010, Dependence of spectral-induced polarization response of sandstone on temperature and its relevance to permeability estimation: Journal of Geophysical Research-Solid Earth, 115, no. B9, B09214. http://dx.doi.org/10.1029/2010jb007526. 


\section{LIST OF FIGURES}

Figure 1. The summit of Hoher Sonnblick (Austria): (a) Map of the summit area showing the locations of geophones, shots and electrodes (red symbols) and the positions of the boreholes (gray circles). Steep walls form the boundaries of the summit pyramid to the North-West (green), North (orange) and East (blue).

Orthophoto published by the government of Carinthia (flights between 2013 and 2015). (b) Aerial photo showing the exposed location of the observatory situated on top of the summit pyramid (provided by Dr. Elke Ludewig). (c) The study area located on the South-East facing slope as seen from the foot of the summit pyramid. (d) Pictures taken during data acquisition illustrating the composition of the debris cover.

Figure 2. Complementary information available for the study area at Hoher Sonnblick.

(a) Thickness of fractured rock layer as obtained from drill logs and the length of rock bolts installed in the three major rock walls. (b) The average air temperature observed between 2014 and 2019. (c) The average active layer thickness (ALT) as derived from rock temperatures collected in borehole A between 2014 and 2018 . Vertical black lines in (b) and (c) illustrate times of ERT and SRT field campaigns. 
Figure 3. Synthetic study comparing different inversion strategies against the true

model. The ability of (a) the structurally constrained PJI and (b) the PJI with structural and porosity constraints to resolve the water, ice, air and rock contents of the synthetic model is evaluated based on five scenarios referring to different assumptions regarding the a priori knowledge of interface depths and porosity distribution, i.e., the effect of wrong a priori information on the inversion results is investigated.

Figure 4. Joint interpretation of results obtained from different geophysical data sets collected at Hoher Sonnblick in 2019. Black circles in (a)-(f) indicate the sensor/shot positions. Seismic Refraction Tomography (SRT) results for data collected in (a) June 2019 and (b) October 2019. Electrical Resistivity Tomography (ERT) results for data collected in (a) June 2019 and (b) October 2019. (e) The radargram collected during the June 2019 Ground-penetrating Radar (GPR) campaign. The resolved subsurface model (f) refers to a three layer case. 
Figure 5. Monthly median borehole temperatures observed in borehole $A$ between 2014 and 2018 (gray lines) and seismic velocities resolved through smoothconstrained inversion in the vicinity of the borehole (color-coded line). The horizontal solid black line illustrates the bedrock depth obtained by Schöner et al. (2012b) through modelling of the thermal diffusivity based on rock temperatures observed in borehole B. The horizontal dashed black line corresponds to the modelled bedrock depth corrected considering the larger debris cover thickness in the vicinity of borehole $A$ (derived from GPR data).

Figure 6. Imaging results for the seismic and electric data sets collected at Hoher Sonnblick in June 2019 and October 2019 resolved through (a) conventional inversion and subsequent transformation by means of a petrophysical model, (b) unconstrained petrophysical joint inversion, and (c) structurally constrained petrophysical joint inversion. Black circles indicate the sensor/shot positions. 
Geophysics

Figure 7. Temporal changes (i.e., absolute differences) between June 2019 and

October 2019 in the imaging results resolved through (a) conventional inversion and subsequent transformation by means of a petrophysical model, (b) unconstrained petrophysical joint inversion, and (c) structurally constrained joint inversion. Black circles indicate the sensor/shot positions.

Figure 8. Subsurface models resolved through structurally constrained petrophysical joint inversion for the electric and seismic data sets collected in (a) June 2019 and (b) October 2019, and (c) the corresponding temporal changes. In the inversions, we prescribed the porosity model resolved for the October 2019 data set obtained through the unconstrained petrophysical joint inversion. Black circles indicate the sensor/shot positions. 
Geophysics

\section{LIST OF TABLES}

Table 1. Petrophysical parameters used for the application of the 4PM and in the

petrophysical joint inversion as obtained from permafrost literature (e.g., Hauck and

Kneisel, 2008).

Table 2. Prior information considered for the assessment of the benefits and

limitations of the constrained PJI approaches. 

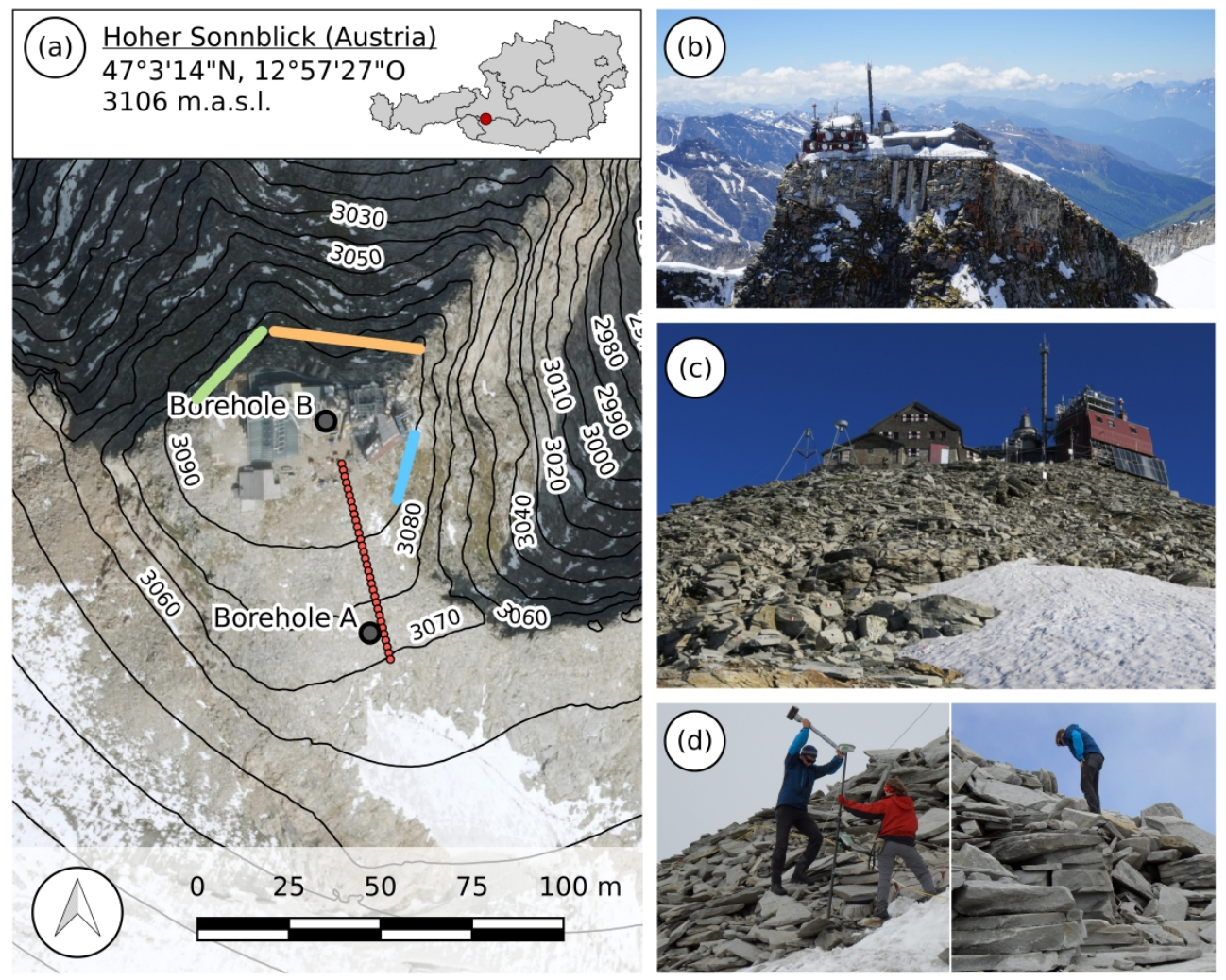

Figure 1. The summit of Hoher Sonnblick (Austria): (a) Map of the summit area showing the locations of geophones, shots and electrodes (red symbols) and the positions of the boreholes (gray circles). Steep walls form the boundaries of the summit pyramid to the North-West (green), North (orange) and East (blue). Orthophoto published by the government of Carinthia (flights between 2013 and 2015). (b) Aerial photo showing the exposed location of the observatory situated on top of the summit pyramid (provided by Dr.

Elke Ludewig). (c) The study area located on the South-East facing slope as seen from the foot of the summit pyramid. (d) Pictures taken during data acquisition illustrating the composition of the debris cover. 

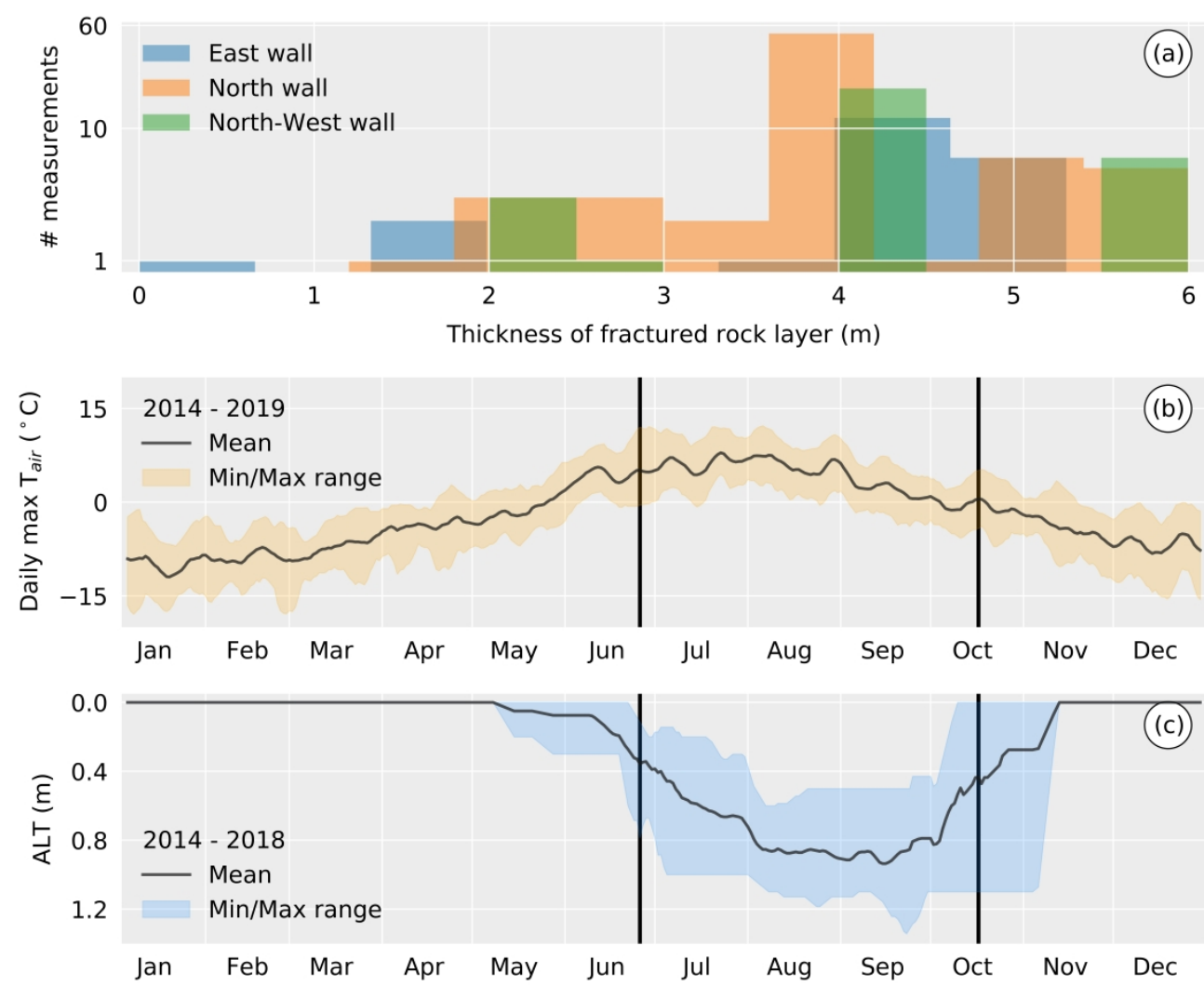

Figure 2. Complementary information available for the study area at Hoher Sonnblick. (a) Thickness of fractured rock layer as obtained from drill logs and the length of rock bolts installed in the three major rock walls. (b) The average air temperature observed between 2014 and 2019. (c) The average active layer thickness (ALT) as derived from rock temperatures collected in borehole A between 2014 and 2018. Vertical black lines in (b) and (c) illustrate times of ERT and SRT field campaigns. 


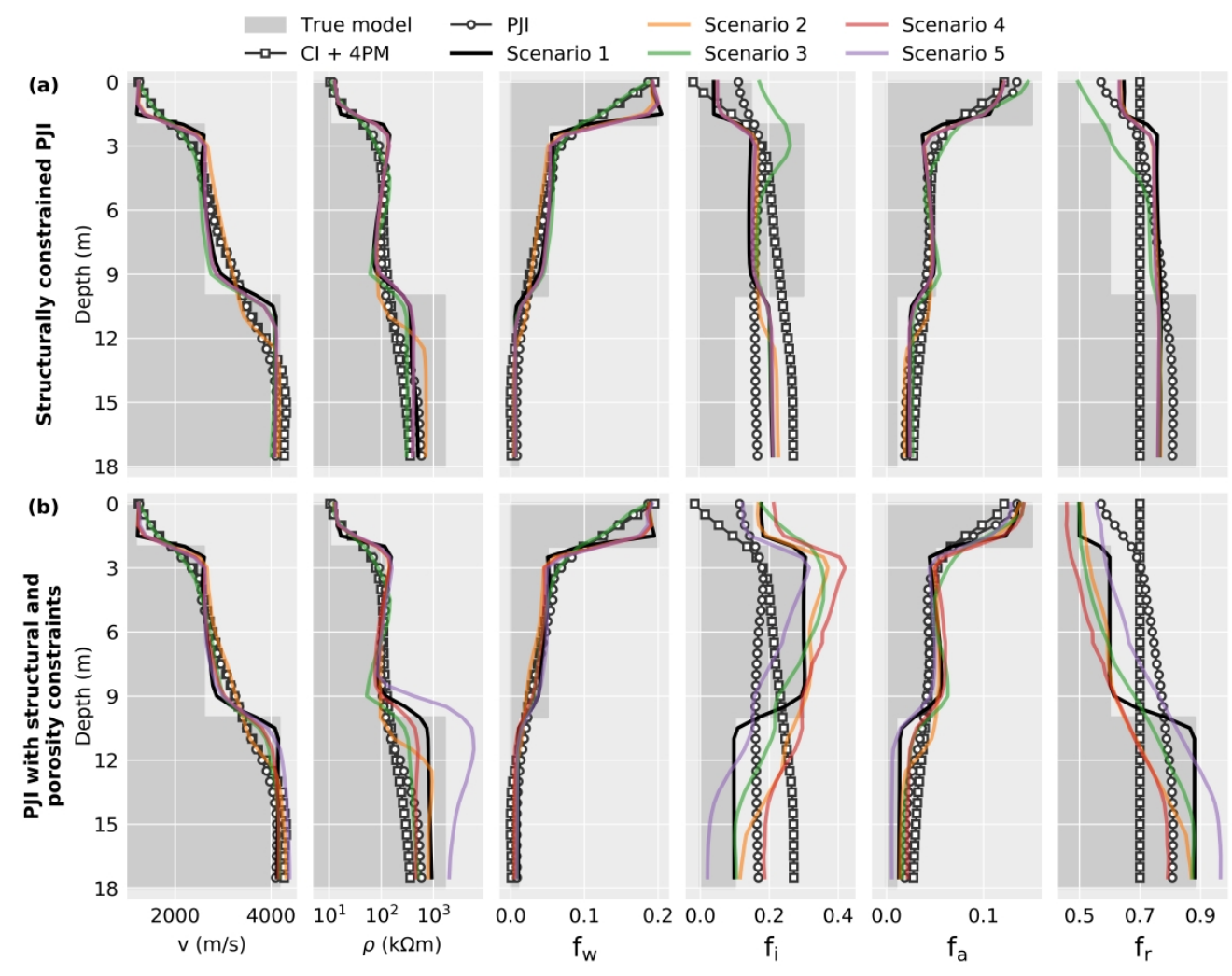

Figure 3. Synthetic study comparing different inversion strategies against the true model. The ability of (a) the structurally constrained PJI and (b) the PJI with structural and porosity constraints to resolve the water, ice, air and rock contents of the synthetic model is evaluated based on five scenarios referring to different assumptions regarding the a priori knowledge of interface depths and porosity distribution, i.e., the effect of wrong a priori information on the inversion results is investigated. 


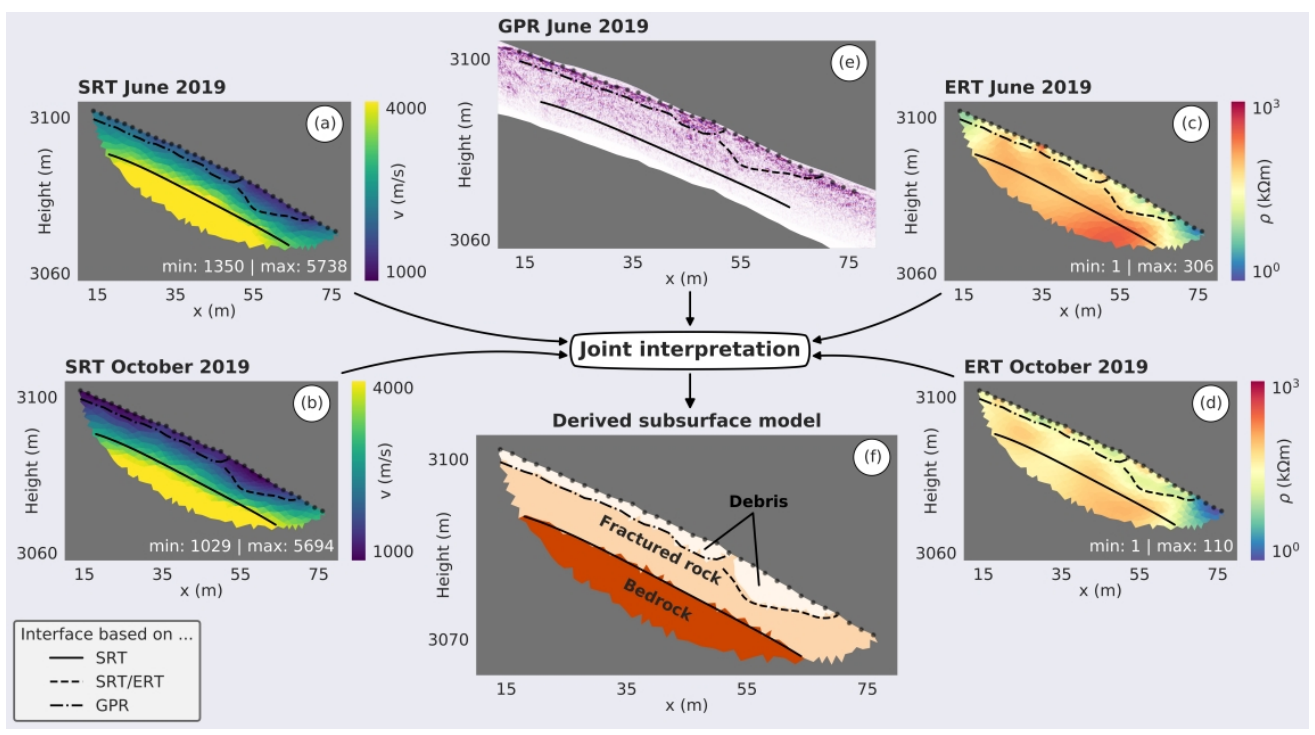

Figure 4. Joint interpretation of results obtained from different geophysical data sets collected at Hoher Sonnblick in 2019. Black circles in (a)-(f) indicate the sensor/shot positions. Seismic Refraction Tomography (SRT) results for data collected in (a) June 2019 and (b) October 2019. Electrical Resistivity Tomography (ERT) results for data collected in (a) June 2019 and (b) October 2019. (e) The radargram collected during the June 2019 Ground-penetrating Radar (GPR) campaign. The resolved subsurface model (f) refers to a three layer case. 


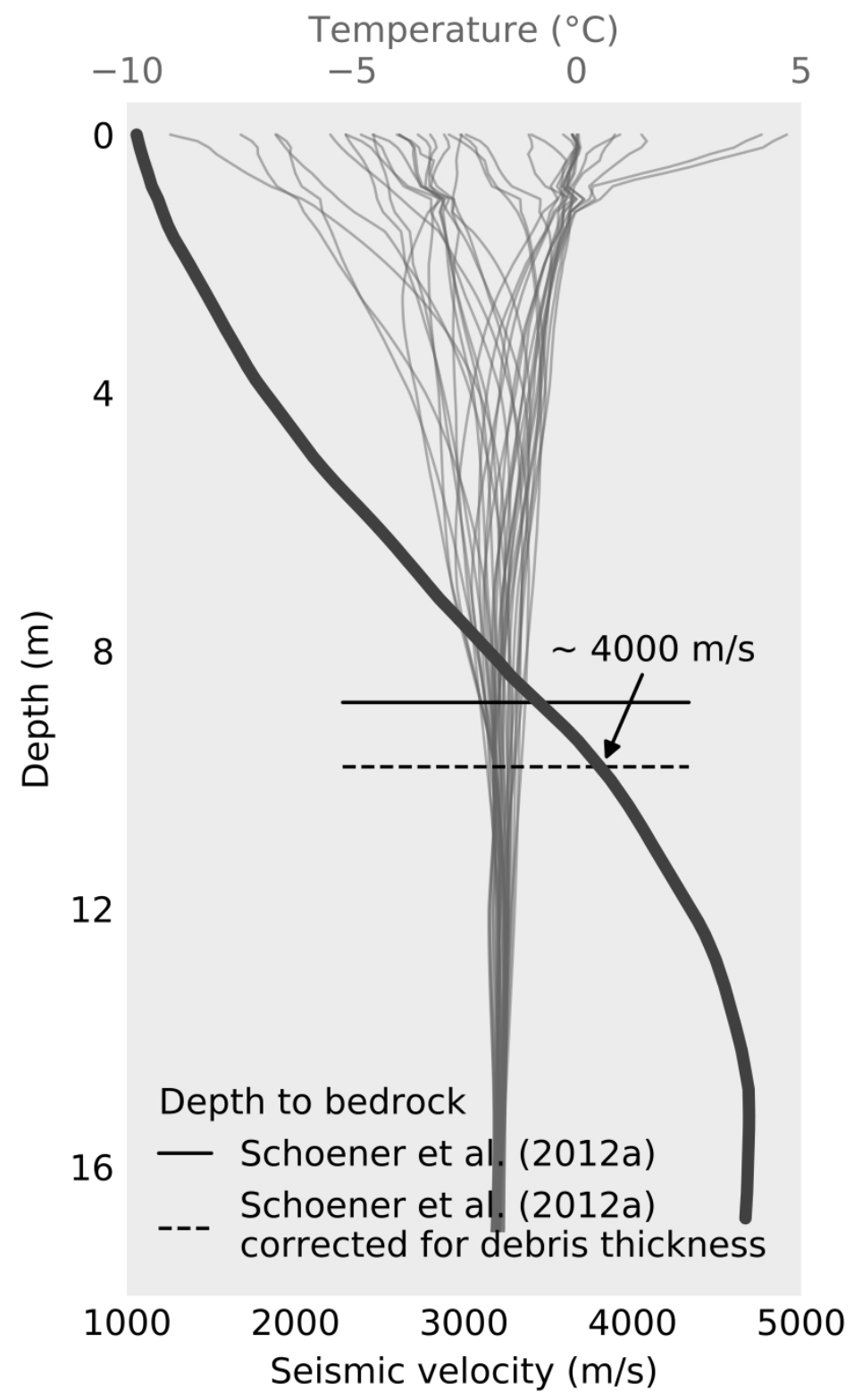

Figure 5. Monthly median borehole temperatures observed in borehole A between 2014 and 2018 (gray lines) and seismic velocities resolved through smooth-constrained inversion in the vicinity of the borehole (color-coded line). The horizontal solid black line illustrates the bedrock depth obtained by Schöner et al. (2012b) through modelling of the thermal diffusivity based on rock temperatures observed in borehole $B$. The horizontal dashed black line corresponds to the modelled bedrock depth corrected considering the larger debris cover thickness in the vicinity of borehole A (derived from GPR data). 


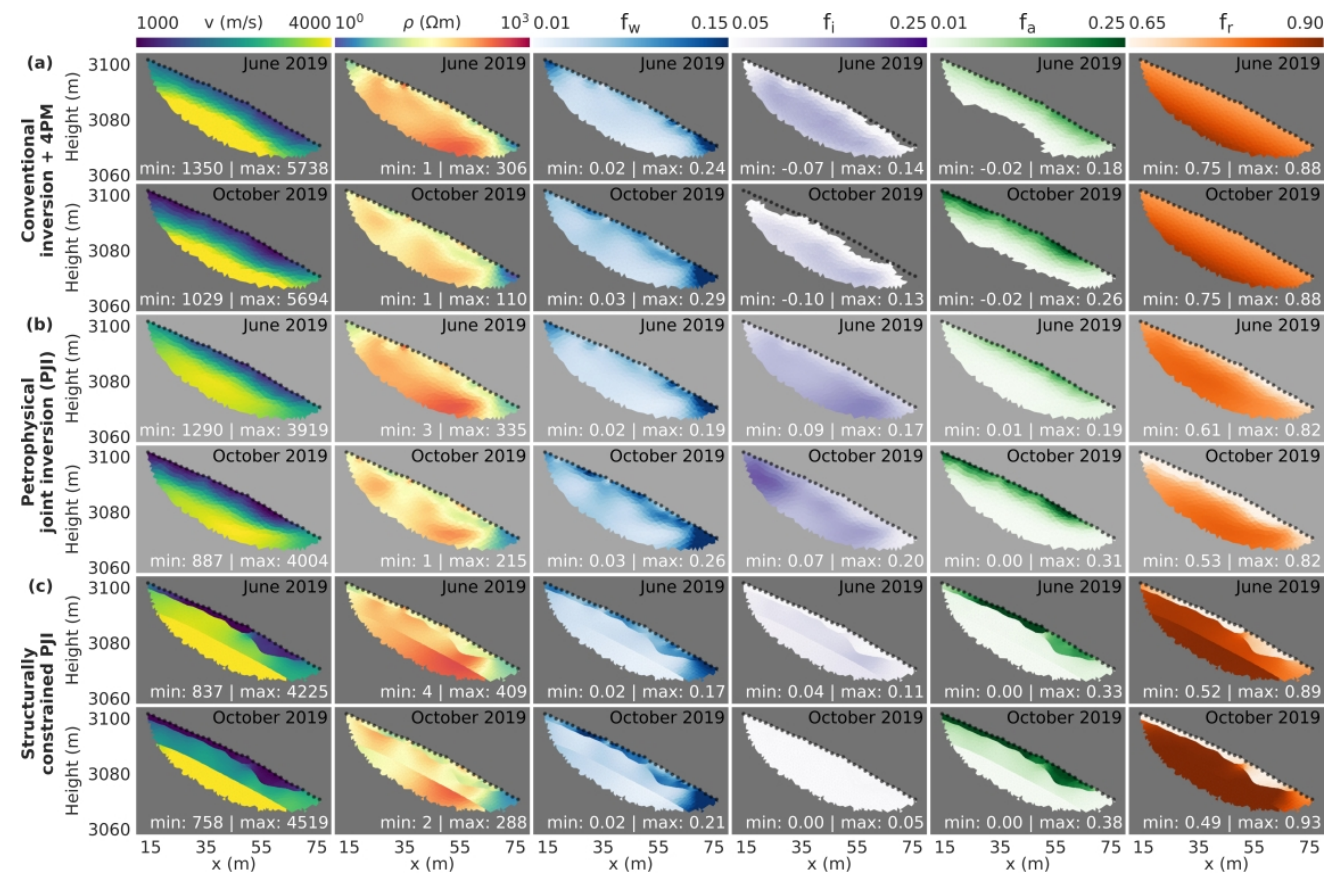

Figure 6. Imaging results for the seismic and electric data sets collected at Hoher Sonnblick in June 2019 and October 2019 resolved through (a) conventional inversion and subsequent transformation by means of a petrophysical model, (b) unconstrained petrophysical joint inversion, and (c) structurally constrained petrophysical joint inversion. Black circles indicate the sensor/shot positions. 


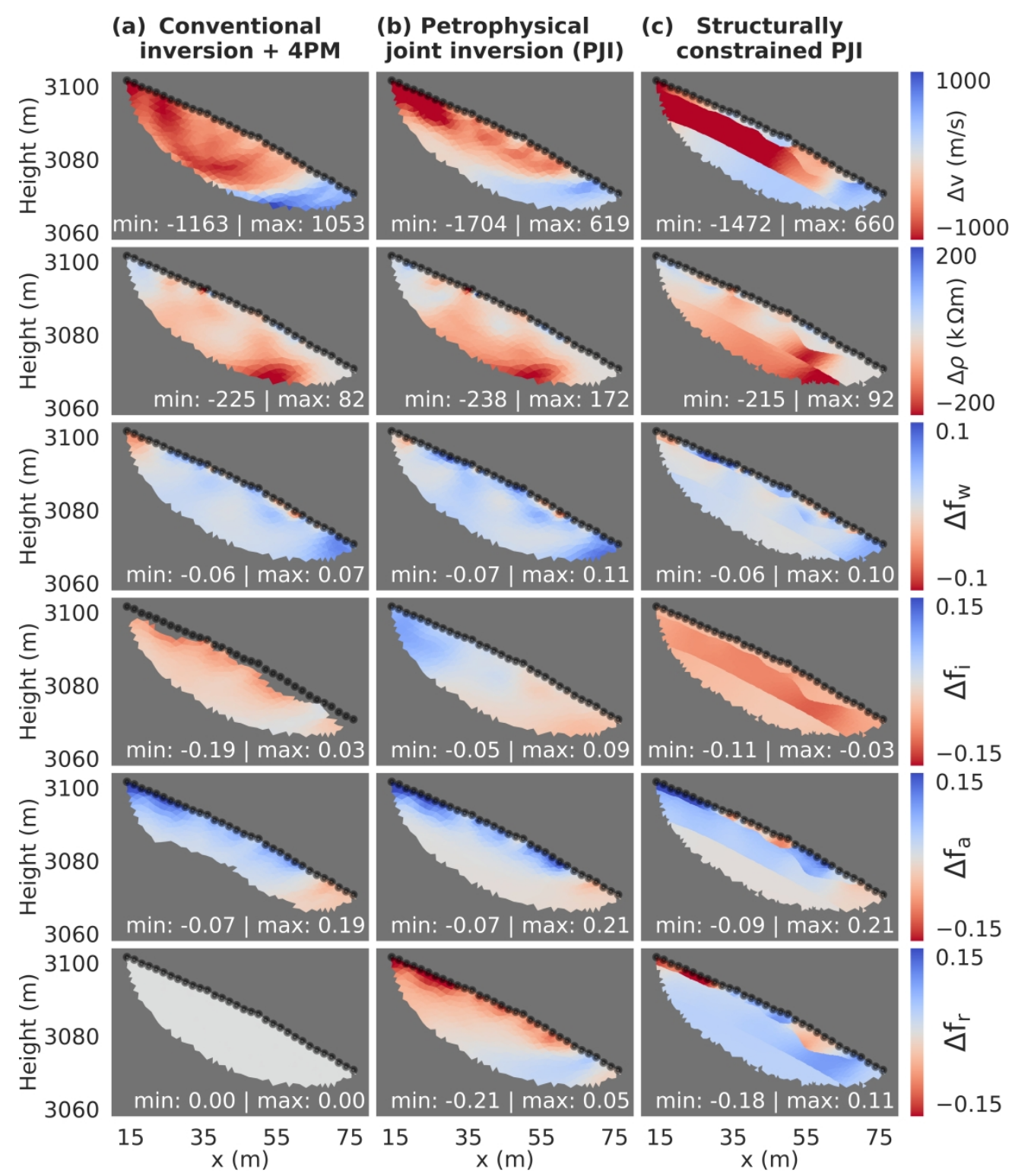

Figure 7. Temporal changes (i.e., absolute differences) between June 2019 and October 2019 in the imaging results resolved through (a) conventional inversion and subsequent transformation by means of a petrophysical model, (b) unconstrained petrophysical joint inversion, and (c) structurally constrained joint inversion. Black circles indicate the sensor/shot positions. 
(a) June 2019

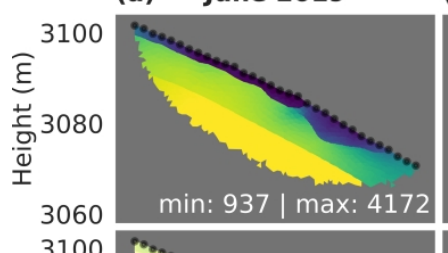

$\widehat{\varepsilon}$

는

喜 3080

3060

$\underline{\xi}$

는

온

3060

छิ$$
\text { है }
$$$$
3060
$$$$
\widehat{\xi}^{310}
$$$$
\text { 苋 } 3080
$$$$
3060
$$$$
\bar{\xi}^{3100}
$$

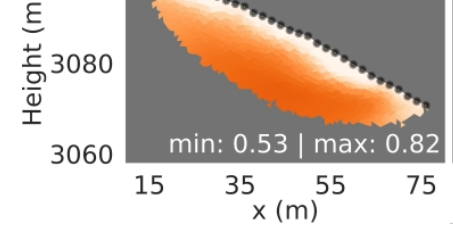

(b) October 2019
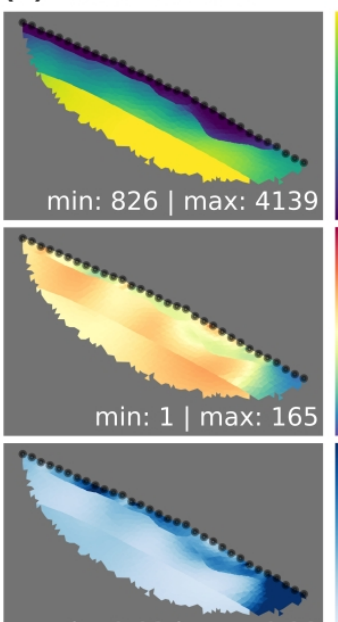

$\min : 0.02 \mid \max : 0.19$

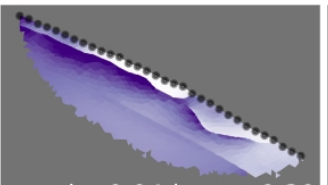

$\min : 0.04$ | max: 0.30

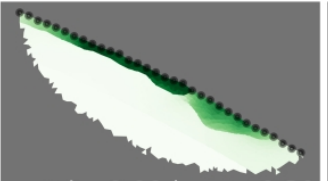

$\min : 0.00 \mid \max : 0.30$
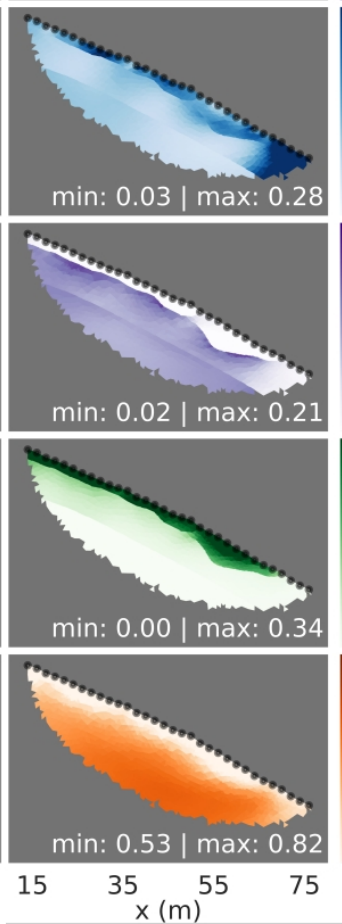

(c) Temporal changes
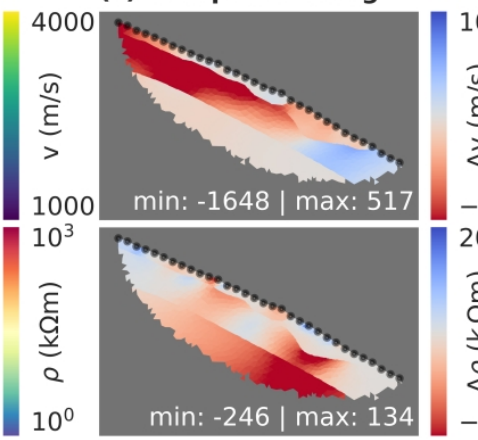

1000

200

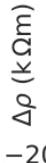

0.1

0.15

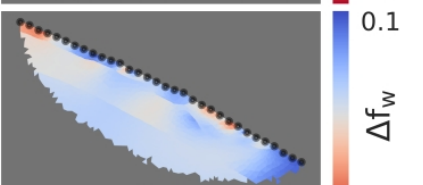

$0.01 \quad \min :-0.07$ | max: $0.09-0.1$

0.25

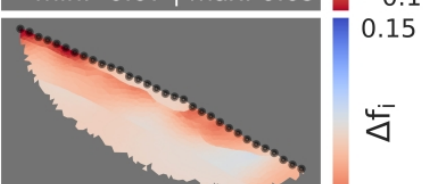

$0.05 \min :-0.16 \mid \max : 0.01-0.15$

0.25
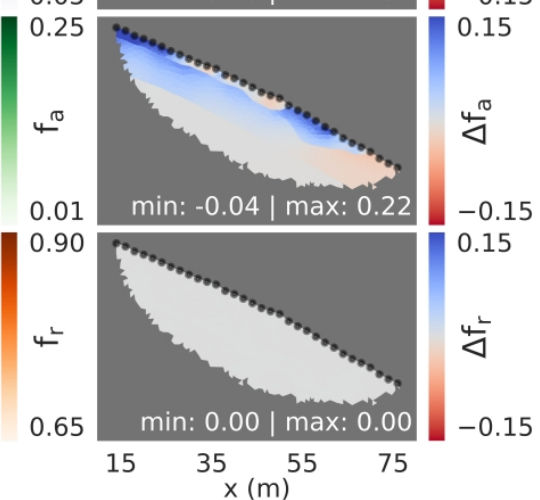

Figure 8. Subsurface models resolved through structurally constrained petrophysical joint inversion for the electric and seismic data sets collected in (a) June 2019 and (b) October 2019, and (c) the corresponding temporal changes. In the inversions, we prescribed the porosity model resolved for the October 2019 data set obtained through the unconstrained petrophysical joint inversion. Black circles indicate the sensor/shot positions. 


\begin{tabular}{|l|l|l|l|l|l|}
\hline \multicolumn{2}{|l|}{ Archie parameters } & \multicolumn{4}{l|}{ Constituent velocities } \\
\hline Parameter & Value & Unit & Parameter & Value & Unit \\
\hline$\rho_{\mathrm{w}}$ & 220 & $\Omega \mathrm{m}$ & $\mathrm{v}_{\mathrm{w}}$ & 1500 & $\mathrm{~ms}^{-1}$ \\
\hline $\mathrm{n}$ & 2.4 & - & $\mathrm{v}_{\mathrm{i}}$ & 3750 & $\mathrm{~ms}^{-1}$ \\
\hline $\mathrm{m}$ & 1.4 & - & $\mathrm{v}_{\mathrm{a}}$ & 330 & $\mathrm{~ms}^{-1}$ \\
\hline & & & $\mathrm{v}_{\mathrm{r}}$ & 5000 & $\mathrm{~ms}^{-1}$ \\
\hline
\end{tabular}




\begin{tabular}{|c|c|c|c|}
\hline Scenario & $\begin{array}{l}\text { Shallow } \\
\text { interface }\end{array}$ & Deep interface & Porosity model \\
\hline 1 & True depth & True depth & True \\
\hline 2 & $+2 \mathrm{~m}$ depth & True depth & $\begin{array}{l}\text { Approximated (kNN smoothing and } \\
\text { random noise) }\end{array}$ \\
\hline 3 & True depth & $+2 \mathrm{~m}$ depth & $\begin{array}{l}\text { Approximated (kNN smoothing and } \\
\text { random noise) }\end{array}$ \\
\hline 4 & True depth & True depth & $\begin{array}{l}\text { Approximated and values } \\
\text { decreased by } 15 \%\end{array}$ \\
\hline 5 & True depth & True depth & $\begin{array}{l}\text { Approximated and values } \\
\text { increased by } 15 \%\end{array}$ \\
\hline
\end{tabular}

